\title{
Glutathione in Cerebral Microvascular Endothelial Biology and Pathobiology: Implications for Brain Homeostasis
}

\author{
Wei Li, Carmina Busu, Magdalena L. Circu, and Tak Yee Aw \\ Department of Molecular and Cellular Physiology, Louisiana State University Health Sciences Center, Shreveport, \\ LA 71130-3932, USA \\ Correspondence should be addressed to Tak Yee Aw, taw@lsuhsc.edu
}

Received 7 March 2012; Accepted 1 May 2012

Academic Editor: Giuseppe Filomeni

Copyright ( 92012 Wei Li et al. This is an open access article distributed under the Creative Commons Attribution License, which permits unrestricted use, distribution, and reproduction in any medium, provided the original work is properly cited.

The integrity of the vascular endothelium of the blood-brain barrier (BBB) is central to cerebrovascular homeostasis. Given the function of the $\mathrm{BBB}$ as a physical and metabolic barrier that buffers the systemic environment, oxidative damage to the endothelial monolayer will have significant deleterious impact on the metabolic, immunological, and neurological functions of the brain. Glutathione (GSH) is a ubiquitous major thiol within mammalian cells that plays important roles in antioxidant defense, oxidation-reduction reactions in metabolic pathways, and redox signaling. The existence of distinct GSH pools within the subcellular organelles supports an elegant mode for independent redox regulation of metabolic processes, including those that control cell fate. GSH-dependent homeostatic control of neurovascular function is relatively unexplored. Significantly, GSH regulation of two aspects of endothelial function is paramount to barrier preservation, namely, GSH protection against oxidative endothelial cell injury and GSH control of postdamage cell proliferation in endothelial repair and/or wound healing. This paper highlights our current insights and hypotheses into the role of GSH in cerebral microvascular biology and pathobiology with special focus on endothelial GSH and vascular integrity, oxidative disruption of endothelial barrier function, GSH regulation of endothelial cell proliferation, and the pathological implications of GSH disruption in oxidative stress-associated neurovascular disorders, such as diabetes and stroke.

\section{Glutathione and Neurovascular Homeostasis}

1.1. Function of the Blood-Brain Barrier. Central to neurovascular homeostasis is the function of the blood-brain barrier (BBB). The BBB is a highly regulated interface between the systemic circulation and brain parenchyma and is comprised of a monolayer of brain capillary endothelial cells on the blood side and perivascular cells on the brain side of microvessels. The BBB functions to protect the parenchymal cells from fluctuations in plasma composition, such as during exercise and following meals, and against circulating neurotransmitters or xenobiotics capable of disrupting neural function [1]. In this regard, the BBB acts as a mechanical barrier; brain capillaries are $\sim 50-100$ times tighter than peripheral microvessels, a property that is attributed to intercellular tight junctions between neighboring endothelial cells that restrict the paracellular diffusion of hydrophilic solutes. Only small molecules such as oxygen and $\mathrm{CO}_{2}$ can freely diffuse across the lipid membranes of the endothelium.

On the luminal and abluminal membranes, specific transport systems regulate the transcellular traffic of small hydrophilic molecules, such as GLUT-1 and L-system carrier 1 in the transport of glucose or leucine, respectively, thereby providing a selective "transport barrier" that facilitates nutrient entry [2]. The highly expressed P-glycoprotein transporter on endothelial luminal surface protects the brain from xenobiotics and the potentially toxic neurometabolite, glutamate. In addition, an enrichment of endothelial degradative enzymes serves as an enzymatic barrier. Examples include ectoenzymes such as peptidases and nucleotidases, which metabolize peptides and ATP, respectively, and the intracellular enzymes monoamine oxidase and cytochrome P450 1A and 2B which inactivate blood-borne neuroactive compounds. Moreover, the cerebral endothelium exhibits 
specific systems for receptor-mediated and adsorptive endocytosis that allow for the transfer of specific peptides and lipoproteins to the brain [2]. Such multiple functions of the BBB regulate the brain microenvironment and maintain parenchymal homeostasis.

1.2. Glutathione Redox System and Cellular Function. The glutathione/glutathione disulfide (GSH/GSSG) couple is the most abundant thiol redox system that plays a key role in the maintenance of the redox environment in cells $[3,4]$. Under physiological conditions, intracellular GSH homeostasis depends on de novo GSH synthesis, GSH redox cycling, and transmembrane GSH transport. Cellular GSH exists mainly in the reduced form with GSSG constituting less than $10 \%$ of the total GSH pool. The biological functions of GSH are attributed to its unique $\gamma$-glutamyl bond between the glutamate and cysteine residues and to the presence of a free thiol group. Reduced GSH is synthesized in the cytosol in two steps from its constituent amino acids (glutamate, cysteine, glycine) catalyzed by $\gamma$-glutamyl cysteine ligase (GCL) and GSH synthase [5]. GCL catalyzes the formation of $\gamma$-glutamylcysteine, the first and rate-limiting reaction in GSH synthesis, and enzyme function is controlled by GSH feedback inhibition or by transcriptional upregulation of enzyme subunits (Section 1.4). An important aspect of cellular GSH homeostasis is that increased GSH oxidation is generally followed by increases in the total pool size, notably through enhanced de novo GSH synthesis.

The versatility of GSH in contributing to a myriad of cellular functions is notable in its role in detoxication reactions (e.g., hydroperoxide and xenobiotic catabolism), regulation of amino acid transport into cells, maintenance of native three-dimensional protein structure in biosynthetic/metabolic processes (e.g., prostaglandins D2 and E2 synthesis), serving as a cofactor for enzyme systems (e.g., glyoxalase I), and redox signaling. Thiol-disulfide exchanges and protein S-glutathiolation are mechanisms by which GSH modulates the oxidative modification of redox active cysteines within proteins and thereby regulates the activity of a variety of enzyme functions, including those controlling proliferation, differentiation, or apoptosis $[6,7]$.

1.2.1. Subcellular Distribution of GSH. Intracellular GSH is differentially distributed among the various subcellular compartments of cytosol, mitochondria, endoplasmic reticulum, and nucleus wherein distinct redox pools are formed $[8,9]$. Cytosolic GSH is highly reduced, and under physiological conditions cytosolic GSH concentrations are between 1 and $11 \mathrm{mM}$ with the GSH to GSSG ratio maintained in excess of 10 to 1 depending on cell types [10]. The redox state of a cell is generally represented by the ratio of GSH to GSSG given the large GSH pool size. Quantitatively, the cytosolic pool accounts for $>70 \%$ of the total cellular GSH, while the nuclear and mitochondrial compartments comprise $10 \%$ to $30 \%$ of the total cellular GSH, respectively [11]. The uniqueness of the nuclear and mitochondrial GSH pools is evidenced by the differences in compartmental GSH turnover rate and sensitivity to chemical depletion [9].
Specifically, the distinct characteristic of the nuclear GSH redox state is consistent with its physiological role in the nucleus, significantly during cell cycle [12] (Section 3.2 below). Indeed, increased nuclear-to-cytosol GSH distribution is a crucial factor in cell proliferation wherein elevated nuclear GSH maintains the functional integrity of the nucleus in gene transcription [13].

While the biological importance of metabolically unique GSH compartments in redox regulation of various endothelial cell functions $[14,15]$ is yet to be fully defined, it can be readily appreciated that such independent GSH pools would afford an elegant mechanism for specific control of redoxsensitive metabolic processes, the failure of which will have significant implications for endothelial pathobiology. The reader is referred to previous excellent reviews for a full discussion of redox compartmentation and its integration in redox signaling $[3,8,15]$.

1.2.2. GSH in Cellular ROS and Redox Signaling. One of the undesired consequences for an organism living in an aerobic environment is an increased potential for oxidative damage by reactive oxygen species (ROS). However, the ability to thrive within such an aerobic environment also implies an evolved capability to handle ROS-mediated tissue damage [16]. The major intracellular sources of ROS, namely, superoxide anion $\left(\mathrm{O}_{2}{ }^{--}\right)$, hydrogen peroxide $\left(\mathrm{H}_{2} \mathrm{O}_{2}\right)$, or hydroxyl radical $\left(\mathrm{HO}^{\bullet}\right)$, are derived from mitochondrial respiration, arachidonic acid pathway, and activities of cellular oxidases, such as cytochrome P450, glucose oxidase, amino acid oxidases, xanthine oxidase, NADH/ NADPH oxidases, or NO synthases $[17,18]$. ROS derived from xenobiotic metabolism or UV/ $\gamma$-radiation are examples of exogenous sources. Elevated ROS levels are damaging to cellular macromolecules like proteins, lipids, and DNA and will induce a state of oxidative stress and redox imbalance [8]. Central to maintaining intracellular redox balance is GSH-dependent ROS elimination that includes GSH peroxidase-catalyzed hydroperoxide metabolism, GSSG reductase-catalyzed, NADPH-dependent GSH regeneration, or GSH S-transferase-catalyzed xenobiotic detoxication [19].

The recognition that ROS can serve as important mediators of cell signaling and that signal transduction may be mediated by ROS-induced GSH redox imbalance is major conceptual breakthrough in our understanding of GSH-dependent redox signaling [20, 21]. Significantly, low ROS levels participate in the signaling of proliferation, senescence, and apoptosis. For instance, $\mathrm{H}_{2} \mathrm{O}_{2}$-targeted proteins containing redox sensitive cysteine residues (P-SH) can result in the formation of reversible sulfenic (P-SOH) as well as irreversible sulfinic $\left(\mathrm{P}-\mathrm{SO}_{2} \mathrm{H}\right)$, and sulfonic $(\mathrm{P}-$ $\left.\mathrm{SO}_{3} \mathrm{H}\right)$ acid derivatives $[22,23]$. The protein sulfenic acid derivative can further react with nitric oxide (NO) to yield nitrosothiol (P-SNO) or with another $\mathrm{P}-\mathrm{SH}$ to form a disulfide bond (P-SS-P) [22, 23]. The latter posttranslational modification, termed S-glutathiolation (also known as Sglutathiolation), refers to the formation of a mixed disulfide between the cysteine of GSH and a cysteine moiety of a protein [6]. Reversible protein cysteine oxidation and protein 


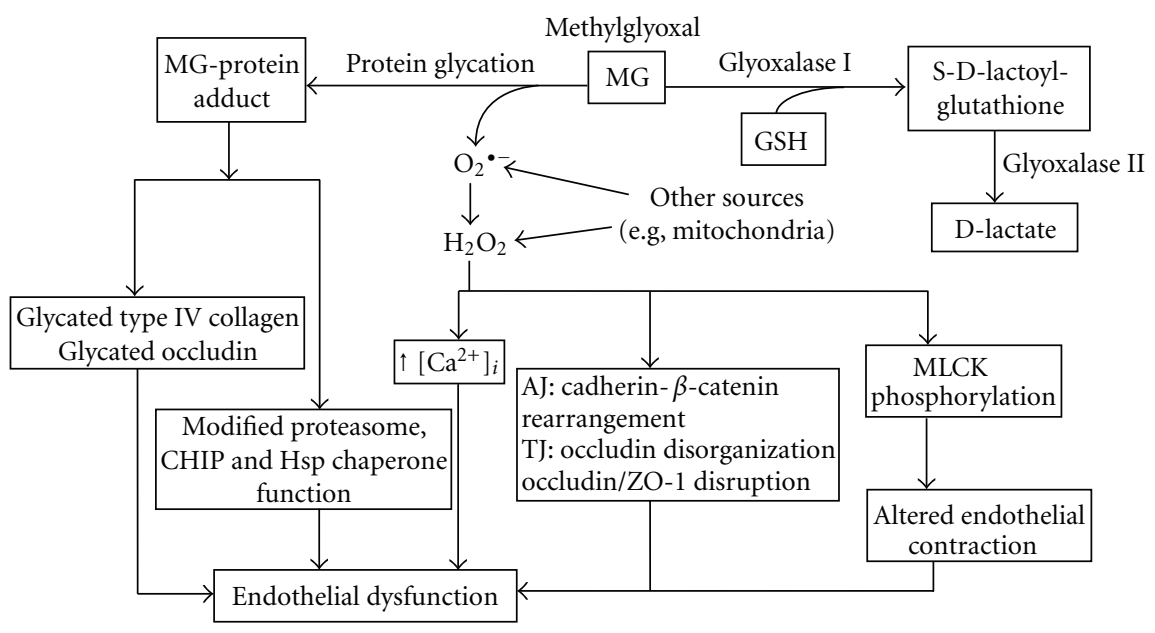

FIGURE 1: Mechanisms of MG-mediated endothelial barrier dysfunction and its protection by GSH. MG-induced endothelial barrier dysfunction can be caused by MG-protein crosslinking (glycation) resulting in the formation of MG-protein adducts, such as tight junction occludin and basement membrane type IV collagen. MG-protein glycation can also modify the proteasomal and chaperone functions. ROS generated during protein glycation can further mediate barrier dysfunction through various pathways: (a) increased intracellular [Ca $\left.{ }^{2+}\right]$, (b) direct disruption of adherens junction and tight junction, or (c) phosphorylation of myosin light chain kinase and altered endothelial cell contraction. Protection of barrier integrity is mediated by GSH, which functions as a cofactor in glyoxalase I-catalyzed metabolism of MG. MG: methylglyoxal, GSH: reduced glutathione, $\mathrm{O}_{2}{ }^{--}$: superoxide anion, $\mathrm{H}_{2} \mathrm{O}_{2}$ : hydrogen peroxide, ROS: reactive oxygen species, AJ: adherens junction, TJ: tight junction, MLCK: myosin light chain kinase.

mixed disulfide formation are catalyzed by the thioredoxin (Trx) and glutaredoxin (Grx) family of redox proteins [6]. This GSH-protein cysteine interaction protects against irreversible protein thiol oxidation and is an important redox mechanism in regulating protein function at low or modest levels of ROS [6]. ROS-dependent protein cysteine oxidation has been implicated in the redox regulation of a wide range of protein functions including enzyme activity, protein expression and abundance, subcellular protein localization, and interaction with other molecular partners in controlling new patterns of cell signaling and gene expression. Viewed simply, control of protein functions by reversible S-glutathiolation/deglutathiolation is akin to that of phosphorylation/dephosphorylation.

\subsection{Endothelial GSH and S-Glutathiolation in the Control of} Vascular Integrity. GSH exerts profound effects on vascular endothelial function, which include endothelial barrier permeability [24], cell apoptosis [25], chemotaxis, angiogenesis $[26,27]$, constitutive and agonist-induced adhesion molecule expression [28], leukocyte-endothelial adhesion response [29], and endothelial dependent vasodilation $[28,30]$. The modulatory effects of GSH are accomplished through the scavenging of ROS [31], an important second messenger in many endothelial functions. For instance, GSH was shown to attenuate $\mathrm{H}_{2} \mathrm{O}_{2}$-induced decrease in transendothelial electrical resistance via negative regulation of the activation of p38 MAP kinase [24]. In other roles, reduced GSH acts as a substrate for the detoxication enzymes, GSH peroxidase, and GSH S-transferase. Our recent studies showed that GSH served as a cofactor in glyoxalase 1-catalyzed detoxication of methylglyoxal and prevented carbonyl stress-induced brain endothelial barrier dysfunction (Figure 1).
A large body of evidence supports a role for Sglutathiolation in redox regulation of vascular function, ranging from cell signaling, apoptosis, protein folding, to cytoskeletal reorganization. In hypertensive vessels, the thiolation of endothelial nitric oxide synthase (eNOS) is pivotal in the redox control of vascular tone. The bioactive nitric oxide (NO) molecule plays a crucial role in normal endothelial function, including modulation of vascular dilator tone, inhibition of platelet activation, inhibition of leukocyte adhesion and migration, and inhibition of smooth muscle cell migration and proliferation [32]. Therefore, altered NO production, such as during oxidative stress, would compromise vascular homeostasis. Oxidative stress has been shown to mediate S-glutathiolation of eNOS that was associated with decreased NOS activity, attenuated NO production, increased $\mathrm{O}_{2}{ }^{\cdot-}$ generation, and impaired endotheliumdependent vasodilation, dysregulated processes that were restored by thiol-specific reducing agents [33]. As for cell signaling, oxidants have been shown to trigger direct $\mathrm{S}$ glutathiolation of p21ras at Cys ${ }^{118}$, which activated p21ras and mediated downstream phosphorylation of ERK and AKT in both endothelial and smooth muscle cells [34, 35]. Similarly, oxidant-induced insulin resistance was mediated through S-glutathiolation of p21ras and ERK-dependent inhibition of insulin signaling [36]. During diamide-induced oxidative stress, activation of endothelial $\mathrm{Ca}^{2+}$ signaling was associated with S-glutathiolation of the inositol-1,4,5trisphosphate (IP3) receptor (IP3R) and the plasmalemmal $\mathrm{Ca}^{2+}$-ATPase pump, which promoted $\mathrm{Ca}^{2+}$ release from IP3sensitive internal $\mathrm{Ca}^{2+}$ stores and elevated basal $\left[\mathrm{Ca}^{2+}\right] \mathrm{i}$ in the absence of extracellular $\mathrm{Ca}^{2+}$ [37].

Current evidence implicates the involvement of Sglutathiolation/deglutathiolation in apoptotic signaling. In 
TNF- $\alpha$-mediated apoptosis, Grx-catalyzed deglutathiolation of procaspase- 3 induced caspase- 3 activation [38]. In Fas-mediated apoptosis, Fas thiolation following caspasedependent Grx1 degradation resulted in the activation of caspases-8 and -3 [39]. Molecular chaperones are an interesting class of proteins that are readily S-glutathiolated wherein thiolated proteins exhibited potentiation of chaperone activities, such as the correct folding of newly synthesized polypeptides [6]. The activities of several Sglutathiolated members of the glucose-related protein (GRP) family of proteins including GRP78, heat shock protein 60 (Hsp60), heat shock cognate $71-\mathrm{kDa}$ protein, and Hsp90 were similarly increased by S-glutathiolation in diamidetreated endothelial cells [40]. Remarkably, even endothelial cytoskeletal reorganization can be modulated by protein Sglutathiolation, notably that of actin and tubulin. Under physiological conditions, S-glutathiolated actin (at Cys ${ }^{374}$ ) inhibited F-actin polymerization, which was reversed by EGF via actin deglutathiolation [41], consistent with a dynamic role of actin assembly/disassembly in the biological process of cell division and cell growth. Notably, actinglutathiolation also occurred under conditions of oxidative stress [42]; in this instance, intracellular actin disassembly or disrupted actin-junctional protein interactions would likely mediate the loss of endothelial barrier function. A role for S-glutathiolated annexin A2-actin interaction is currently unknown. Similarly, while S-glutathiolation of endothelial $\beta$ tubulin has been reported [40], the biological importance of this modification in endothelial barrier function remains to be defined.

1.4. GSH Regulation: Transcriptional Control of GCLc and GCLm Expression. GCL-catalyzed de novo synthesis is central to the preservation of tissue GSH balance, particularly during oxidative stress. GCL is a heterodimeric protein composed of catalytic (GCLc) and modifier (GCLm) subunits. The GCLc subunit alone possesses all of the catalytic activities of the enzyme; however, heterodimerization with the GCLm subunit increases GCL activity $\left(V_{\max }\right.$ and $K_{\text {cat }}$ ), substrate affinity $\left(K_{m}\right)$ for glutamate and ATP, and the $K_{i}$ for GSH feedback inhibition [43]. Metabolic regulation of GCL is mediated by protein phosphorylation at serine and threonine moieties, which inhibits enzyme activity and transcriptional control of GCL function is through the expression of the catalytic and modulatory subunits.

1.4.1. Regulation of GCL Catalytic (GCLc) and Modifier $(G C L m)$ Subunits. The promoters of GCLc and GCLm subunits share common elements and coordinate transactivation results in overall increase in subunit expression. Key mediators of GCL expression are the redox sensitive transcription factors, nuclear factor kappa B (NF- $\kappa$ B), Sp-1, activator protein-1 and -2 (AP-1, AP-2), and nuclear factor E2-related factor 2 (Nrf2) [44]. The promoter of the human $G C L c$ gene contains consensus binding sites for AP-1, NF$\kappa \mathrm{B}, \mathrm{Nrf2}$, and for the antioxidant response (ARE) or electrophile responsive (EpRE) elements [44]. A proximal AP-1 element was crucial for the transcription of GCLc induced by oxidative stress [45] while NF- $\kappa \mathrm{B}$ was essential in TNF $\alpha$ mediated increase in GCLc transcription either directly or indirectly via transactivation of AP-1 sites through induction of C-Jun expression [43]. Among the four AREs in the human GCLc promoter, ARE4 was important in the constitutive expression of hepatic GCLc induced by $\beta$-naphthoflavone $(\beta$-NF) or cytochrome P450 2E1 [46, 47]. In macrophages, elevated GCLc expression caused by homocysteine was mediated by ARE4 and the MERKERK1/2 kinase pathway [48]. Involvement of the PI3 kinase pathway was also described in adrenomedullin-induced transcriptional activation of the GCLc promoter [49]. Recent studies from our laboratory demonstrated a role for Nrf2 in the constitutive and insulin-induced endothelial GCLc expression [50]. Insulin-induced GCLc promoter activation was ARE4 dependent [51]. Significantly, the increase in GCL activity and GSH synthesis via insulin signaling and activation of the PI3K/Akt/mTOR/Nrf2/GCLc pathway prevented hyperglycemia-induced endothelial apoptosis [52]. Interestingly, rat GCLc promoter exhibited only three AREs in the $5^{\prime}$-flanking region, of which ARE3 was involved in Nrf2-dependent expression of GCLc [53], suggesting species differences in ARE requirements for GCLc activation.

Constitutive or induced posttranslational phosphorylation of GCLc further contributes to GCL control. In contrast to insulin and hydrocortisone, which induced GCLc gene expression [17], stress hormones such as glucagon and phenylephrine caused GCLc phosphorylation through activating the protein kinases, $\mathrm{PKA}, \mathrm{PKC}$, or $\mathrm{Ca}^{2+}$-calmodulin kinase $[54,55]$. Notably, GCLc phosphorylation decreased GCLc activity.

The transcriptional regulation of GCLm is poorly understood. Current evidence shows that the human GCLm promoter also contained an ARE site that mediated Nrf2dependent GCLm upregulation induced by $\beta$-NF and lipid peroxidation products $[56,57]$. In rat liver, an ARE element similarly mediated the basal and $\mathrm{TNF} \alpha$-induced of the GCLm promoter activity [58]. Additionally, the rat GCLm promoter has an AP-1 consensus site for constitutive and tert-butylhydroquinone-induced GCLm expression. For reasons yet unclear, $\mathrm{NF} \kappa \mathrm{B}$-dependent GCLm expression appeared to be linked to AP-1 activation within the GCLc promoter [43], suggesting possible cross-talk between the two promoters in subunit expression.

\section{Oxidative Challenge and Endothelial Barrier Dysfunction}

2.1. Influence of Reactive Oxygen Species (ROS). It is abundantly clear that oxidative stress induced by ROS such as $\mathrm{O}_{2}{ }^{\bullet-}$, $\mathrm{HO}^{\bullet}$, or $\mathrm{H}_{2} \mathrm{O}_{2}$ can elicit endothelial barrier dysfunction. Moreover, oxidative stress also increased intracellular endothelial calcium concentration $\left(\left[\mathrm{Ca}^{2+}\right] \mathrm{i}\right)[59,60]$; in pulmonary artery endothelial cells, the blockade of $\mathrm{Ca}^{2+}$ entry abolished oxidative stress-induced solute permeability [61], indicating that oxidative stress was linked to elevated $\left[\mathrm{Ca}^{2+}\right] \mathrm{i}$, an important modulator of endothelial permeability (Figure 1). In addition, oxidants like $\mathrm{H}_{2} \mathrm{O}_{2}$ were shown to 
increase the phosphorylation of myosin light chain kinase [62], suggesting that ROS can alter endothelial contraction and contribute to endothelial barrier dysfunction (Figure 1). This means that oxidant modulation of the cytoskeletal architecture of the endothelial monolayer could be central to the loss of barrier integrity. Moreover, increased ROS concentrations can decrease NO bioavailability through chemical inactivation to form the powerful oxidizing agent, peroxynitrite [63]. Tetrahydrobiopterin (BH4), a critical cofactor for eNOS function, is a crucial target for oxidation by peroxynitrite [64]. Significantly, BH4 oxidation and depletion were shown to induce eNOS uncoupling, a process that was associated with increased $\mathrm{O}_{2}{ }^{\bullet-}$ generation and decreased NO production. In this regard, uncoupled eNOS is akin to a dysfunctional $\mathrm{O}_{2}{ }^{--}$generating enzyme that could contribute to endothelial oxidative stress and vascular dysfunction. The uncoupling of eNOS has been demonstrated in vitro and in hypertensive rat (SHR) models of cardiovascular pathophysiology, such as angiotensin-IIinduced hypertension and diabetes [65].

Control of paracellular permeability in the endothelium is a function of the intercellular endothelial adherens junctions (AJ) and tight junctions (TJ), a complex structure comprised of specific junctional proteins. The cadherins, $\alpha-$ catenin, and $\beta$-catenin proteins are components of the AJ, while the transmembrane proteins, occludin, claudin, junction adhesion molecule, and the cytoplasmic accessory zonula occludin (ZO-1, -2 , and -3 ) proteins comprised the TJ [66]. $\mathrm{H}_{2} \mathrm{O}_{2}$-induced barrier disruption has been shown to occur through rearrangement of endothelial cadherin and $\beta$-catenin and the disruption of $\beta$-catenin/cytoskeletal association [67], but the signaling events are unresolved. However, activation of ERK1/ERK2 signaling and occludin phosphorylation were shown to mediate the disorganization of occludin and the disruption of occludin-ZO-1 interactions on endothelial cell surfaces [68]. ROS activation of signaling pathways, such as PKC, may further regulate the phosphorylation state of other $\mathrm{AJ}$ and $\mathrm{TJ}$ proteins. In this regard, a reversal of thrombin-induced loss of the cadherin junctional proteins, $\rho$-catenin, $\alpha$-catenin, and p120, by PKC inhibitor has been described [69].

2.2. Role of Carbonyl Stress. Carbonyl stress is the result of enhanced reactive carbonyl species (RCS) production and decreased carbonyl-scavenging capability, leading to tissue accumulation of reactive dicarbonyl species, such as methylglyoxal (MG). MG is produced from cellular glycolytic intermediates and can induce carbonyl stress through irreversible reaction with free arginine residues of proteins to form advanced MG-glycated end product (AGE) [70] (Figure 1). The generation of protein carbonyls or proteinglycated products could be a major problem in diabetic neurovascular pathology. An MG-derived argpyrimidine adduct has been detected in human lens and kidney and in atherosclerotic lesions of diabetic patients [71-73], and argpyrimidine-modified heat shock protein 27 (Hsp 27) was shown to alter diabetic endothelial cell function [74]. Moreover, diabetes-associated hyperglycemia and MG-induced modification of the corepressor $m \operatorname{Sin} 3 A$ gene were linked to elevated angiopoietin-2 transcription in microvascular endothelial cells [75]. Other evidence revealed that the modification of $20 \mathrm{~S}$ proteasome by MG decreased proteasomal chymotrypsin-like activity and impaired the CHIP and chaperone-dependent quality control of the protein [76], leading to the accumulation of toxic aggregates and endothelial cell death. Further, MG-induced glycation of vascular basement membrane type IV collagen yielded hotspots of arginine-derived hydroimidazolone residues at RGD and GFOGER integrin-binding sites, causing endothelial cell detachment, anoikis, and inhibition of angiogenesis [77].

The crosslinking of MG and amino acids was shown to yield the $\mathrm{O}_{2}{ }^{--}$radical anion [78] that can be quenched by $\mathrm{O}_{2}{ }^{\bullet-}$ scavenger and membrane-permeable catalase [79]. Significantly, MG-derived ROS has important implications for vascular and endothelial function. It is noteworthy that MGinduced mitochondrial $\mathrm{O}_{2}{ }^{--}$generation stimulated eNOS activity [79], while MG-mediated eNOS phosphorylation (at $\operatorname{ser}^{1777}$ ) attenuated endothelial NO production [80], suggesting that carbonyl stress modulation of endogenous endothelial NO production is a complex process. In rat carotid arterial endothelium MG was found to augment AT1R-induced NADPH oxidase-derived mediated $\mathrm{O}_{2}{ }^{-{ }^{-}}$and $\mathrm{H}_{2} \mathrm{O}_{2}$ production, which increased Ang II-dependent vascular contraction [81]. Similarly, MG-derived ROS mediated the oxidative and hyperglycemic stress-induced impairment of endothelium-dependent vasorelaxation. This oxidative stress response was attenuated by the overexpression of glyoxalase I which promoted MG degradation [82]. In recent studies, we found that MG-occludin glycation induced barrier dysfunction of human brain microvascular endothelial cells; surprisingly, MG-dependent endogenous ROS generation did not contribute majorly to barrier dysfunction. Our study further revealed that the endothelial GSH status is a determinant of barrier integrity by facilitating glyoxalase Icatalyzed MG metabolism and thereby decreasing the availability of free MG ( $\mathrm{Li}$ and Aw, unpublished data, Figure 1). Moreover, GSH depletion significantly promoted MGinduced endothelial oxidative stress and cell apoptosis [25, 83].

Altered cell morphology, aberrant cytoskeletal rearrangement, and ZO-1 loss were notable biological consequences of glyoxal, another sugar-derived aldehyde product. Additionally, glyoxal also elicited mitochondrial dysfunction, inhibition of DNA and cell replication, and cell cytotoxicity through protein carbonyl formation [84]. Collectively, these findings underscore the wide-ranging cellular effects of carbonyl stress on vascular endothelial function.

\section{Endothelial Repair through Proliferation and Growth}

3.1. Biology of Cell Cycle Control. Cell cycle control is crucial for proper postdamage endothelial repair and growth. The mammalian cell cycle is characterized by a quiescent $\mathrm{G}_{0}$ phase of nondividing cells followed by cell entry into the cell cycle at $G_{1}$ and progression through the $S, G_{2}$, and $M$ phases 


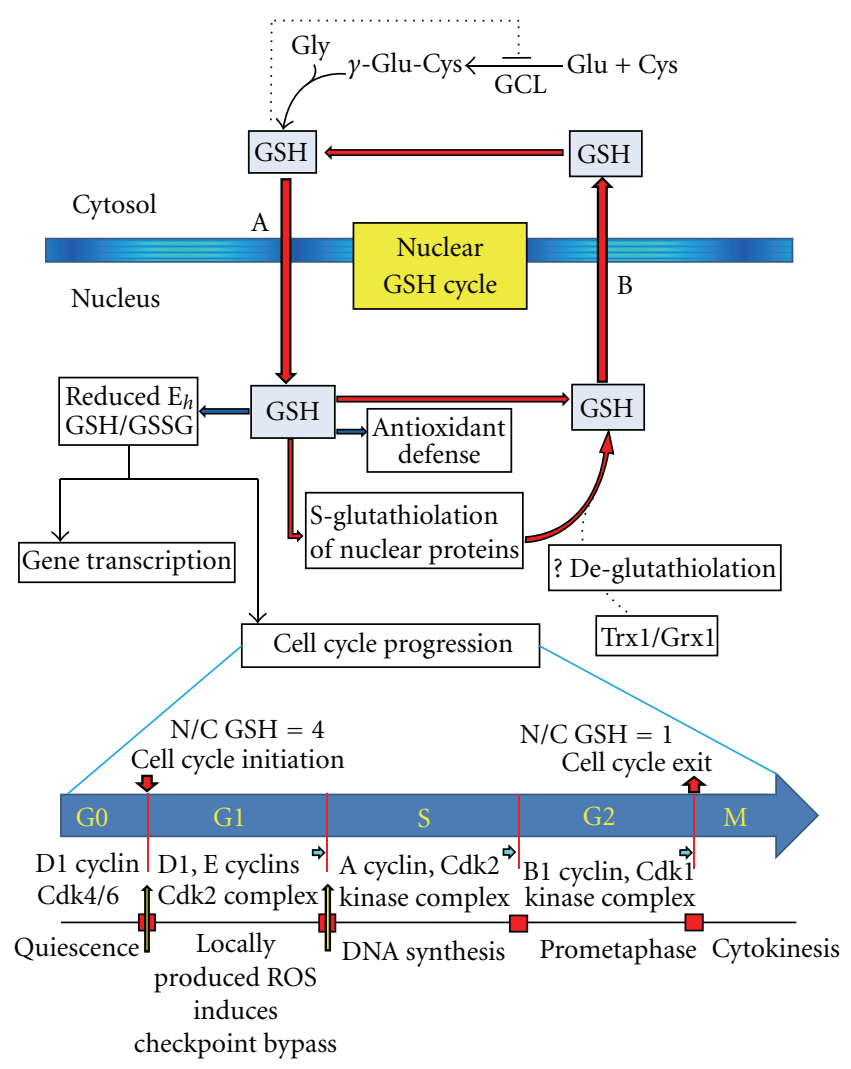

FIGURE 2: Nuclear glutathione cycle and associated redox changes during cell cycle progression. A nuclear GSH cycle is established during cell cycle progression that involves the dynamic partitioning of cellular GSH between the nuclear and cytosolic compartments. Cell entry into the cycle in early $\mathrm{G}_{1}$ is associated with sequestration of GSH into the nucleus (A). At this stage of cell cycle initiation, the nuclearto-cytosol (n/c) GSH ratio approximates 4. The transient decrease in cytosolic GSH releases feed-back inhibitory effect of GSH on GCL activity and triggers de novo GSH synthesis, a process that continues until the feedback control is reestablished. Sequestered intranuclear GSH exists in the reduced form or bound to nuclear proteins, which together changes the GSH/GSSG redox potential ( $\left.E_{h}\right)$ in favor of gene transcription and cell cycle-associated DNA synthesis/replication. Free GSH functions in antioxidant defense that protects against oxidative DNA damage during DNA replication. As yet unclear, free GSH may be regenerated via deglutathiolation of thiolated nuclear proteins, likely catalyzed by Trx1 and/or Grx1. The dissolution of the nuclear envelope in the prometaphase and cytokinesis (cell cycle exit) induces nuclear-to-cytosol GSH export (B) resulting in equal GSH distribution (n/c = 1) in the two compartments in the newly divided cells. Redoxdependent activation of regulatory checkpoints governs cell exit from quiescence (cyclin D1 and associated Cdk4), entry into and progression through cell cycle (cyclin E1-Cdk2, cyclin A-Cdk2 kinase complexes), and final exit from cell cycle (cyclin B1-Cdk1 kinase complex) (blue arrows). Additionally the checkpoints at the $\mathrm{G}_{0} / \mathrm{G}_{1}$ or $\mathrm{G}_{1}$-to-S transitions can be bypassed by locally generated ROS (yellow arrows). GSH: glutathione, GSSG: glutathione disulfide, GCL: $\gamma$-glutamate cysteine ligase; n/c: nuclear-to-cytosol, Trx1: thioredoxin1, Grx1: glutaredoxin 1, and Cdk: cyclin-dependent kinase.

in response to environmental or cellular cues that overcome the biological constraint of a mitotic block [20]. DNA replication takes place during the $S$ phase, and accurate replication commits cell progression into the $M$ phase while aberrant DNA replication induces transient $\mathrm{G}_{2}$ arrest that allows for DNA repair [85]. Failure of DNA repair initiates cell cycle withdrawal and permanent senescence. Cell progression through the cell division cycle is governed by regulatory checkpoints controlled by specific serine/threonine cyclin-dependent kinases (CDKs) and their respective cyclin subunits. Specifically, the checkpoints for cell transitions from $G_{0} / G_{1}$ to $S$, late $G_{1}$ to early $S, S$ to $G_{2}$, and $G_{2}$ to $M$ are, respectively, regulated by $D$-type cyclin D1, D2 and associated with CDK4-6, cyclin E1/CDK2 complex, cyclin A/CDK2 kinase complex, and cyclin B1/CDK1 kinase complex in association with Cdc25 phosphatase [86] (Figure 2).

3.2. Glutathione and Cell Cycle Regulation. The progression of cells through the cell cycle has been linked to dynamic changes in the intracellular redox environment particularly that of the GSH/GSSG redox couple from a more oxidized state prior to cell cycle initiation to a more reduced state throughout cell cycle until cell cycle exit after prometaphase and cytokinesis (Figure 2). Specifically, studies have documented that cell exit from the quiescent stage at $\mathrm{G}_{0}$ /early $\mathrm{G}_{1}$ and entry into cell cycle was characterized by a relatively more oxidizing milieu $[87,88]$ than that during progression from $G_{1}$ through $S$ to $G_{2} / M[87,89]$. The redox status of cysteine residues of cell cycle regulatory 
proteins and their functions were highly sensitive to the intracellular redox environment, which is impacted by cellular production and/or removal of ROS [86]. For example, in actively dividing cells, redox-dependent activation of specific cyclin/CDKs complexes by locally produced ROS allowed for checkpoint bypass at the $G_{1}$ restriction point or at late $G_{1}$ to $S$ transition $[7,14,90]$. Similarly, growth-factor-mediated ROS production and redox regulation of $\mathrm{p} 16, \mathrm{p} 27$, and cyclin D1, which drove terminally differentiated cells into cell cycle $[91,92]$, governed the reentry of quiescent cells into the cell cycle $[91,92]$. E2F, pRB, MAP kinase, Cdc25 phosphatase, and cyclin are other important cell cycle proteins shown to undergo redox changes and/or modifications during cell cycle progression [90, 93-95].

A role for ROS in mitogenic signaling is underscored by the finding that treatment of serum-starved cells with the thiol antioxidant, N-acetylcysteine (NAC), elicited cell cycle arrest at $G_{1}$, a delay of $G_{0}$ to $G_{1}$ progression that correlated with defective redox control [92]. Interestingly, during exponential growth of cultured mouse embryonic fibroblasts, NAC treatment arrested cells at the $G_{1}$ to $S$ transition but allowed cell transit through the $S, G_{2}$, and $M$ phases [96], indicating that redox control at the early event at $G_{1}$ governed cell progression from $G_{1}$ to $S$. An increase in MnSOD activity was implicated in NAC-induced inhibition of $G_{1}$ to $S$ entry [90]. Collectively, these studies illustrate the importance of ROS in mitogenic signaling during cell cycle, a redox process that appears to be coordinated through defined cellular mechanisms for ROS generation and elimination. A reduced intracellular redox environment protected genomic DNA from oxidative damage upon breakdown of the nuclear envelope [89] and was therefore essential to enhance DNA synthesis during cell transition from $G_{1}$ to $G_{2} / M$. Early accumulation of soluble thiols at the mitotic spindle was observed during mitosis in sea urchin eggs [97]. Similarly a graduation of low to high GSH content was associated with the transition of Chinese hamster ovary fibroblasts through $G_{1}$ to $S$ to $G_{2} / M$ [89], consistent with a well-defined dynamics of redox changes in the intracellular environment during cell cycle.

Intracellular redox homeostasis is maintained by the thiol/disulfide redox systems of GSH/GSSG, thioredoxin ( $\operatorname{Tr} x / \operatorname{TrSS}$ ), and cysteine (Cys/CySS). The product of reducing potential and reducing capacity of the redox couples determined the cellular redox environment, which in most cells are largely governed by that of the GSH/GSSG couple [4]. Indeed, the cellular GSH/GSSG redox status provides a good quantitative indicator of the intracellular redox state, often expressed as the redox potential, $E_{h}$. Under physiological conditions, $E_{h}$ for GSH/GSSG, as calculated by the Nernst equation, is between $-260 \mathrm{mV}$ and $-200 \mathrm{mV}$ [15]. Notably, a change in GSH/GSSG $E_{h}$ from a reduced value of $\sim 260 \mathrm{mV}$ to an oxidized value of $-170 \mathrm{mV}$ was associated with phenotypic cell transition from proliferation to growth arrest and apoptosis [15]. As discussed in Section 1.2.1, specificity of redox signaling and independent redox regulation of the functions of single proteins or protein sets are in part attributed to the existence of distinct compartments of GSH within the subcellular organelles.
Recent evidence suggests that the dynamic cytosol-tonuclear GSH distribution was a crucial factor in cell cycle progression in that nuclear GSH accumulation provided an intranuclear redox environment that enabled proper regulation of redox signaling events during the various stages of the cell cycle [13]. A novel concept of a nuclear GSH cycle that operated during cell cycle has been proposed [98] as illustrated in Figure 2. According to this hypothesis, GSH was recruited and sequestrated into nucleus in early $\mathrm{G}_{1}$ phase, likely through a BcL-2-dependent import mechanism [99]. Increased cytosolic-to-nuclear GSH translocation transiently caused GSH imbalance within the cytosol that initiated de novo GSH synthesis, resulting in progressive increases in the total cytosolic GSH pool. Cell transition through $\mathrm{G}_{2} / \mathrm{M}$ and the dissolution of the nuclear envelope during mitosis enabled the reequilibration of the cytosolic and nuclear GSH pools, and this return to a pre-cell cycle nuclear-to-cytosolic GSH ratio of 1 to 1 was maintained in non-proliferating cells at $G_{0} / G_{1}$. It was further proposed that it was the transient decrease in cytosolic GSH that promoted early $\mathrm{G}_{1}$ signaling. Moreover, the increased GSH presence in the nucleus during the $S$ phase coincided with the activation of DNA replication as evidenced by elevated S-glutathiolation of histones, telomerase, and polyADP ribose polymerase [13, 100]. Additionally, DNA synthesis and replication could be further facilitated by GSH-dependent reorganization of the nuclear matrix and chromatin structure [101]. The details of GSH control of cell cycle checkpoints during endothelial cell proliferation are sketchy and are the subjects of current investigation in our laboratory.

\subsection{Glutathione Disruption and Implications for Endothelial} Growth and Repair. As an organ that is highly dependent on oxidative metabolism for its energy needs, the brain is susceptible to tissue GSH imbalance and oxidative damage mediated by increased formation of free radical species and lipid peroxidation $[102,103]$. Given the location of the $\mathrm{BBB}$ at the interface between brain parenchyma and systemic blood, the endothelial monolayer is easily exposed to the oxidizing conditions of elevated ROS or RCS associated with various pathological states (Section 4 below). Additionally, an often decreased tissue or systemic GSH level under these diseased states would enhance oxidative damage to the vascular endothelium and the consequent loss of vascular integrity will have important implications for cerebral homeostasis. The enzyme $\gamma$-glutamyl transpeptidase $(\gamma$-GT) is regarded as a marker of BBB integrity in the mammalian brain. It is noteworthy that $\gamma$-GT levels were lowest in the more primitive regions of the brain and highest in the more specialized regions of the brain [104], the reason of which is yet unknown. Importantly, within the brain, the microvesicular fractions exhibited significantly higher $\gamma$-GT activity than the neuronal or glial fractions, consistent with a microvesicular localization of the enzyme [104]. However, $\gamma$-GT activity in type I cells ("cobblestone" phenotype) increased 10-12-fold after glial stimulation, indicating a role for type I cells in BBB function as well [105]. Equally notable was the finding that membrane-associated $\gamma$-GT 
activity in the endothelium of capillaries was higher than that in larger vessels in the brain, implying that cerebral small vessel endothelial monolayers will likely be more sensitive to fluctuations in the plasma GSH levels in terms of both susceptibility to injury and efficiency of repair. Furthermore, given that $\gamma$-GT can catalyze the metabolism of not only GSH but also S-nitrosoglutathione (GSNO), cerebral microvascular $\gamma$-GT function could be pivotal in mediating the bioactivity of GSNO and/or NO (Section 4.2).

The findings that GSH levels in endothelial cells in culture increased during the lag phase, were elevated during the initial exponential growth phase, and then fell as cells become confluent [106] suggest that systemic GSH interruption would alter endothelial growth. Our recent studies in human microvascular endothelial cells showed that inhibition of GSH synthesis and GSH depletion elicited a delayed S-to- $\mathrm{G}_{2}$ transition reflected in a lengthening of the cell cycle S-phase resident time (Busu and Aw, unpublished), in agreement with previous observations [107]. Significantly, cellular GSH depletion was largely confined to the cytosolic pool while the nuclear GSH compartment remained relatively unchanged. Somewhat surprisingly, delayed S-to- $\mathrm{G}_{2}$ transition remained evident for $6 \mathrm{~h}$ despite the restoration of cytosolic GSH synthetic capacity and near normalization of basal cellular GSH levels (Busu and Aw, unpublished), consistent with a significant time lag between restored cellular redox balance and recovery of normal cell cycle activity. The reason for this temporal dissociation is unclear and is currently under investigation in our laboratory. What is clear, however, is that through perturbing cell cycle events, a disruption in cellular GSH such as that occuring during oxidative or carbonyl stress could delay endothelial proliferation and tissue repair following oxidative damage to the endothelium, a deleterious scenario for brain function in cerebrovascular and neurodegenerative disorders.

\section{Pathological Implications of Impaired Glutathione in Neurovascular Disease States}

4.1. Neurovascular Pathology of Diabetes. Increased BBB permeability has been demonstrated in patients with type II diabetes [108] and in the streptozotocin- (STZ-) induced type I diabetic experimental rat model [109]. Elevated activities of plasma metalloproteinases 2 and 9 were implicated in the loss of tight junctional proteins (occludin, claudin-5, ZO-1, and JAM-1) and BBB failure [110]. Interestingly, the receptor for AGE (RAGE) was upregulated during diabetes [111], suggesting that increased plasma-to-cellular MG uptake and enhanced GSH-dependent intracellular MG catabolism could provide a means to attenuate the elevated systemic MG levels associated with the diabetic state. BBB disruption was notable during diabetic ketoacidosis wherein neurovascular inflammation, accompanying CCL-2 chemokine expression, NF- $\kappa \mathrm{B}$ activation, and nitrotyrosine formation were likely contributors to the attenuated BBB integrity and increased barrier permeability [112]. In STZ-induced diabetic rats, $\mathrm{BBB}$ function was improved by the administration of growth hormone and insulin $[113,114]$. Our recent studies demonstrated that insulin-mediated protection of human microvascular endothelial cells against MG-induced apoptosis was the result of increased intracellular GSH through activation of the insulin-PI3K/Akt/mTOR/Nrf2/GCLc signaling pathway $[50,52]$.

It is well known that diabetes is associated with hyperglycemia, elevated oxidative and carbonyl stress, and low tissue and plasma levels of GSH [115-120], conditions that complicate the diabetic state, which would lead to further exacerbation of GSH loss. Thus, mechanisms that promote neurovascular GSH status or those that attenuate oxidative and/or carbonyl stress could preserve endothelial barrier function. A viable approach could involve activation of insulin signaling to maintain cellular GSH balance and support GSH-dependent attenuation of oxidative or carbonyl stress mediated by ROS or MG [25, 51, 52, 121]. Furthermore, increasing GSH protection of redox sensitive thiols of membrane proteins, including those of the AJ or TJ, could preserve the functional integrity of the endothelium. The question of whether acute or chronic GSH therapy would be effective in abrogating systemic hyperglycemialinked oxidative and carbonyl stress and mitigate diabetesassociated $\mathrm{BBB}$ dysfunction remains an open question that warrants further investigation.

4.2. Microvascular Dysfunction in Stroke. Stroke is a cerebrovascular disorder wherein a blood clot or interrupted blood flow to a region of the brain leads to a rapid loss of brain function. Significantly, a lack or delayed flux of oxygen and glucose to the brain will result in neuronal death and brain damage. Clinical studies have shown that subjects at risk for stroke exhibited low tissue GSH levels and decreased GSH-to-GSSG ratio and that the restoration of normal cerebral GSH balance could be as long as $72 \mathrm{~h}$ after the ischemic insult $[122,123]$. Importantly, acute ischemic stroke was associated with elevated oxidative stress, a major contributor to immediate and delayed ischemic brain injury and changes in the parenchymal GSH redox status [124, 125]. An increase in free radical production during acute cerebral ischemia can arise from multiple sources including stimulation of N-methyl-D-aspartate receptors [126], mitochondrial dysfunction [127], activation of neuronal NO synthase (NOS) [128, 129], autooxidation of catecholamines, and metabolism of free fatty acids [130]. The activation and migration of inflammatory cells, such as neutrophils, further contributed to $\mathrm{O}_{2}{ }^{--}$and $\mathrm{H}_{2} \mathrm{O}_{2}$ generation [130].

The restoration of endothelial integrity after thrombotic or hemorrhagic stroke is crucial to preserving BBB function and neurovascular homeostasis. The proliferation of endothelial cells adjacent to the lesion or injury site is a pivotal step. Given the role of GSH in cell proliferation (Section 3), maintaining cellular GSH balance is therefore essential for postdamage endothelial repair and wound healing. S-nitrosoglutathione (GSNO) is an important physiological metabolite produced by the reaction of $\mathrm{NO}$ with GSH [131] that is involved in NO storage and release through the function of $\gamma$-GT [132]. The affinity of $\gamma$-GT 
for GSNO $\left(K_{m}\right.$ of $\left.0.4 \mathrm{mM}\right)$ was comparable to other $\gamma$ glutamyl substrates [132], suggesting a physiological role for $\gamma$-GT-in GSNO metabolism. Whether high micromolar concentrations of GSNO are achievable in cells remains uncertain. However, recent studies demonstrated that, at least in plasma, GSNO levels are likely to be higher than previously reported due to the presence of exogenous $\gamma$-GT [133], further underscoring the significance of the enzyme in modulating GSNO levels and bioactivity.

Reportedly, GSNO functions in cellular signaling [134, 135] and protection of the central nervous system (CNS) against excitotoxicity, inflammation, and ROS [136, 137]. Notably, GSNO protection against peroxynitrite-induced oxidative stress is severalfold more potent than GSH [138]. GSNO-mediated CNS protection against inflammation appeared to be through suppressing iNOS induction and promoting eNOS expression, and maintaining cerebral blood flow [139]. The anti-inflammatory activity of GSNO in downregulating iNOS was mediated by inhibition of NF$\kappa \mathrm{B}$ activation and decreased expression of ICAM- 1 and ED- 1 . Additionally, the expression of ZO-1 and occludin at endothelial tight junctions was enhanced by GSNO treatment [140]. Unlike conventional NO donors that mediate quick NO release, GSNO elicits slow NO release that was implicated in neurovascular protection against ischemia reperfusion [141]. In addition to $\gamma$-GT, S-nitrosoglutathione reductase (GSNOR), which catalyzes the reduction of GSNO, has been shown to be an important regulator of the endogenous GSNO levels and NO bioactivity. The pathophysiological role of GSNOR in SNO signaling and $\mathrm{NO}$ bioactivity in the regulation of vascular tone is incompletely understood; recent evidence suggests that GSNOR regulates airway SNO levels in cell signaling [142] and protects against nitrosative stress and cancer risk in human lung [143]. This notwithstanding, it remains unclear whether therapeutic strategies involving exogenous GSH and/or NO supplementation during neurovascular inflammatory conditions, such as stroke, would be clinically efficacious in the short term in attenuating the oxidative burden and protecting the $\mathrm{BBB}$, or in the long term in reducing brain edema and tissue damage.

\section{Summary and Perspective}

The integral function of the microvascular endothelium underpins cerebrovascular homeostasis. ROS- and/or RCSinduced endothelial dysregulation is an underlying concern in barrier failure, and, as such, much research has focused on the use of antioxidants as a strategy to attenuate oxidative or carbonyl stress and restore monolayer function. The finding that GSH, a major cellular antioxidant, is able to afford cytoprotection supports the notion that antioxidant therapy is important in endothelial barrier preservation. In past years, more recent conceptual advances in redox cell biology have uncovered a fundamental role of GSH in signal transduction and redox signaling in cellular functions. Moreover, the finding that distinct pools of GSH exist in subcellular organelles that allow for independent redox regulation has revolutionized our thinking of GSH-dependent redox mechanisms in controlling metabolic processes. One such biological process is that of cell proliferation. In the context of enhanced endothelial proliferation and self-repair surrounding lesion sites in response to systemic cues, for example, growth factors, little is known of a role for GSH. The dynamics of cytosol-to-nuclear GSH distribution appears to be pivotal in governing cell cycle responses. The notion that cell proliferation and growth can be a relevant biological process for monolayer repair/restitution following endothelial injury in much the same way as epithelial cell restitution/proliferation restores postinjured epithelium suggests exciting new avenues for future research in endothelial biology. Importantly, an understanding of GSH control of endothelial cell proliferative potential under different oxidizing conditions and plasma GSH levels will expand our perspective for future development of therapeutic strategies. Targeting endothelial restoration after oxidative insult and tissue damage is likely to be clinically relevant to the neurovascular disorders of diabetes and stroke and additionally could have broader implications for neurodegenerative and neurological disorders as well.

\section{Abbreviations}

AGE: advanced glycated end product

AJ: $\quad$ Adherens junctions

AP-1: Activator protein-1

AP-2: Activator protein-2

ARE: Antioxidant response element

BBB: Blood-brain barrier

CDK: Cyclin-dependent kinases

CNS: Central nervous system

Cys: Cysteine

CySS: Cystine

$E_{h}$ : Redox potential

eNOS: Endothelial nitric oxide synthase

EpRE: Electrophile responsive element

GCL: $\quad \gamma$-glutamyl cysteine ligase

GCLc: GCL catalytic subunit

GCLm: GCL modifier subunit

GRP: $\quad$ Glucose-related protein

Grx: Glutaredoxin

GSH: Glutathione

GSNO: S-nitrosoglutathione

GSNOR: S-nitrosoglutathione reductase

GSSG: Glutathione disulfide

$\mathrm{H}_{2} \mathrm{O}_{2}$ : Hydrogen peroxide

Hsp27: Heat shock protein 27

Hsp60: Heat shock protein 60

IP3: Inositol-1,4,5-trisphosphate

IP3R: IP3 receptor

MG: Methylglyoxal

NAC: $\quad \mathrm{N}$-acetylcysteine

NF- $\kappa$ B: Nuclear factor kappa B

NO: $\quad$ Nitric oxide

NOS: $\quad$ NO synthase

Nrf2: $\quad$ Nuclear factor E2-related factor 2

$\mathrm{O}_{2}{ }^{\bullet-}$ : $\quad$ Superoxide anion radical

RCS: Reactive carbonyl species 
ROS: Reactive oxygen species

STZ: Streptozotocin

TJ: Tight junctions

Trx: Thioredoxin

ZO: Zonula occluding protein

$\beta$-NF: $\beta$-naphthoflavone.

\section{Authors' Contribution}

W. Li and C. Busu, contributed equally.

\section{Conflict of Interests}

The authors declare no conflict of interests.

\section{Acknowledgment}

Research in the authors' laboratory is supported by a Grant from the National Institutes of Health, DK44510.

\section{References}

[1] N. J. Abbott and I. A. Romero, "Transporting therapeutics across the blood-brain barrier," Molecular Medicine Today, vol. 2, no. 3, pp. 106-113, 1996.

[2] N. J. Abbott, P. A. Revest, and I. A. Romero, "Astrocyteendothelial interaction: physiology and pathology," Neuropathology and Applied Neurobiology, vol. 18, no. 5, pp. 424433, 1992.

[3] Y. M. Go and D. P. Jones, "Redox compartmentalization in eukaryotic cells," Biochimica et Biophysica Acta, vol. 1780, no. 11, pp. 1273-1290, 2008.

[4] F. Q. Schafer and G. R. Buettner, "Redox environment of the cell as viewed through the redox state of the glutathione disulfide/glutathione couple," Free Radical Biology and Medicine, vol. 30, no. 11, pp. 1191-1212, 2001.

[5] A. Meister and M. E. Anderson, "Glutathione," Annual Review of Biochemistry, vol. 52, pp. 711-760, 1983.

[6] I. Dalle-Donne, R. Rossi, D. Giustarini, R. Colombo, and A. Milzani, "S-glutathionylation in protein redox regulation," Free Radical Biology and Medicine, vol. 43, no. 6, pp. 883-898, 2007.

[7] M. Fratelli, E. Gianazza, and P. Ghezzi, "Redox proteomics: identification and functional role of glutathionylated proteins," Expert Review of Proteomics, vol. 1, no. 3, pp. 365-376, 2004.

[8] M. L. Circu and T. Y. Aw, "Reactive oxygen species, cellular redox systems, and apoptosis," Free Radical Biology and Medicine, vol. 48, no. 6, pp. 749-762, 2010.

[9] M. L. Circu and T. Y. Aw, "Glutathione and apoptosis," Free Radical Research, vol. 42, no. 8, pp. 689-706, 2008.

[10] O. W. Griffith, "Biologic and pharmacologic regulation of mammalian glutathione synthesis," Free Radical Biology and Medicine, vol. 27, no. 9-10, pp. 922-935, 1999.

[11] J. M. Lluis, A. Morales, C. Blasco et al., "Critical role of mitochondrial glutathione in the survival of hepatocytes during hypoxia," Journal of Biological Chemistry, vol. 280, no. 5, pp. 3224-3232, 2005.

[12] R. M. Green, M. Graham, M. R. O’Donovan, J. K. Chipman, and N. J. Hodges, "Subcellular compartmentalization of glutathione: correlations with parameters of oxidative stress related to genotoxicity," Mutagenesis, vol. 21, no. 6, pp. 383390, 2006.

[13] J. Markovic, C. Borras, A. Ortega, J. Sastre, J. Vina, and F. V. Pallardo, "Glutathione is recruited into the nucleus in early phases of cell proliferation," Journal of Biological Chemistry, vol. 282, no. 28, pp. 20416-20424, 2007.

[14] J. M. Hansen, Y. M. Go, and D. P. Jones, "Nuclear and mitochondrial compartmentation of oxidative stress and redox signaling," Annual Review of Pharmacology and Toxicology, vol. 46, pp. 215-234, 2006.

[15] M. Kemp, Y. M. Go, and D. P. Jones, "Nonequilibrium thermodynamics of thiol/disulfide redox systems: a perspective on redox systems biology," Free Radical Biology and Medicine, vol. 44, no. 6, pp. 921-937, 2008.

[16] M. Genestra, "Oxyl radicals, redox-sensitive signalling cascades and antioxidants," Cellular Signalling, vol. 19, no. 9, pp. 1807-1819, 2007.

[17] H. Cai and D. G. Harrison, "Endothelial dysfunction in cardiovascular diseases: the role of oxidant stress," Circulation Research, vol. 87, no. 10, pp. 840-844, 2000.

[18] T. Finkel, "Reactive oxygen species and signal transduction," International Union of Biochemistry and Molecular Biology Life, vol. 52, no. 1-2, pp. 3-6, 2001.

[19] D. A. Dickinson and H. J. Forman, "Glutathione in defense and signaling: lessons from a small thiol," Annals of the New York Academy of Sciences, vol. 973, pp. 488-504, 2002.

[20] T. Y. Aw, "Molecular and cellular responses to oxidative stress and changes in oxidation-reduction imbalance in the intestine," American Journal of Clinical Nutrition, vol. 70, no. 4, pp. 557-565, 1999.

[21] J. W. Langston, M. L. Circu, and T. Y. Aw, "Redox signaling and vascular function," in Neurovascular Medicine Pursuing Cellular Longevity for Healthy Aging, chapter 19, pp. 473-507, Oxford University Press, New York, NY, USA, 2009.

[22] S. Biswas, A. S. Chida, and I. Rahman, "Redox modifications of protein-thiols: emerging roles in cell signaling," Biochemical Pharmacology, vol. 71, no. 5, pp. 551-564, 2006.

[23] Y. Wang, J. Yang, and J. Yi, "Redox sensing by proteins: oxidative modifications on cysteines and the consequent events," Antioxidant and Redox Signaling, vol. 16, no. 7, pp. 649-657, 2012.

[24] P. V. Usatyuk, S. Vepa, T. Watkins, D. He, N. L. Parinandi, and V. Natarajan, "Redox regulation of reactive oxygen speciesinduced p38 MAP kinase activation and barrier dysfunction in lung microvascular endothelial cells," Antioxidants and Redox Signaling, vol. 5, no. 6, pp. 723-730, 2003.

[25] M. Okouchi, N. Okayama, and T. Y. Aw, "Preservation of cellular glutathione status and mitochondrial membrane potential by $\mathrm{N}$-acetylcysteine and insulin sensitizers prevent carbonyl stress-induced human brain endothelial cell apoptosis," Current Neurovascular Research, vol. 6, no. 4, pp. 267278, 2009.

[26] W. Langston, J. H. Chidlow, B. A. Booth et al., "Regulation of endothelial glutathione by ICAM-1 governs VEGF-Amediated eNOS activity and angiogenesis," Free Radical Biology and Medicine, vol. 42, no. 5, pp. 720-729, 2007.

[27] H. Ashino, M. Shimamura, H. Nakajima et al., "Novel function of ascorbic acid as an angiostatic factor," Angiogenesis, vol. 6, no. 4, pp. 259-269, 2003.

[28] S. Kokura, R. E. Wolf, T. Yoshikawa, D. N. Granger, and T. Y. Aw, "Molecular mechanisms of neutrophil-endothelial cell adhesion induced by redox imbalance," Circulation Research, vol. 84 , no. 5 , pp. 516-524, 1999. 
[29] C. G. Kevil, H. Pruitt, T. J. Kavanagh et al., "Regulation of endothelial glutathione by ICAM-1: implications for inflammation," FASEB Journal, vol. 18, no. 11, pp. 1321-1323, 2004.

[30] K. Kugiyama, M. Ohgushi, T. Motoyama et al., "Intracoronary infusion of reduced glutathione improves endothelial vasomotor response to acetylcholine in human coronary circulation," Circulation, vol. 97, no. 23, pp. 2299-2301, 1998.

[31] S. K. Biswas, D. E. Newby, I. Rahman, and I. L. Megson, "Depressed glutathione synthesis precedes oxidative stress and atherogenesis in Apo-E-/- mice," Biochemical and Biophysical Research Communications, vol. 338, no. 3, pp. 13681373, 2005.

[32] D. Tousoulis, A. M. Kampoli, C. Tentolouris, N. Papageorgiou, and C. Stefanadis, "The role of nitric oxide on endothelial function," Current Vascular Pharmacology, vol. 10, no. 1, pp. 4-18, 2012.

[33] C. A. Chen, T. Y. Wang, S. Varadharaj et al., "S-glutathionylation uncouples eNOS and regulates its cellular and vascular function," Nature, vol. 468, no. 7327, pp. 1115-1120, 2010.

[34] N. Clavreul, T. Adachi, D. R. Pimental, Y. Ido, C. Schöneich, and R. A. Cohen, "S-glutathiolation by peroxynitrite of p21ras at cysteine-118 mediates its direct activation and downstream signaling in endothelial cells," FASEB Journal, vol. 20, no. 3, pp. 518-520, 2006.

[35] T. Adachi, D. R. Pimentel, T. Heibeck et al., "S-glutathiolation of Ras mediates redox-sensitive signaling by angiotensin II in vascular smooth muscle cells," Journal of Biological Chemistry, vol. 279, no. 28, pp. 29857-29862, 2004.

[36] N. Clavreul, M. M. Bachschmid, X. Hou et al., "S-glutathiolation of $\mathrm{p} 21 \mathrm{ras}$ by peroxynitrite mediates endothelial insulin resistance caused by oxidized low-density lipoprotein," Arteriosclerosis, Thrombosis, and Vascular Biology, vol. 26, no. 11, pp. 2454-2461, 2006.

[37] J. T. Lock, W. G. Sinkins, and W. P. Schilling, "Effect of protein S-glutathionylation on $\mathrm{Ca}^{2+}$ homeostasis in cultured aortic endothelial cells," American Journal of Physiology, vol. 300, no. 2, pp. H493-H506, 2011.

[38] S. Pan and B. C. Berk, "Glutathiolation regulates tumor necrosis factor- $\alpha$-induced caspase- 3 cleavage and apoptosis: key role for glutaredoxin in the death pathway," Circulation Research, vol. 100, no. 2, pp. 213-219, 2007.

[39] V. Anathy, S. W. Aesif, A. S. Guala et al., "Redox amplification of apoptosis by caspase-dependent cleavage of glutaredoxin 1 and S-glutathionylation of Fas," Journal of Cell Biology, vol. 184, no. 2, pp. 241-252, 2009.

[40] C. Lind, R. Gerdes, Y. Hamnell et al., "Identification of Sglutathionylated cellular proteins during oxidative stress and constitutive metabolism by affinity purification and proteomic analysis," Archives of Biochemistry and Biophysics, vol. 406, no. 2, pp. 229-240, 2002.

[41] J. Wang, E. S. Boja, W. Tan et al., "Reversible glutathionylation regulates actin polymerization in A431 cells," Journal of Biological Chemistry, vol. 276, no. 51, pp. 47763-47766, 2001.

[42] I. Dalle-Donne, R. Rossi, D. Giustarini, R. Colombo, and A. Milzani, "Actin S-glutathionylation: evidence against a thioldisulphide exchange mechanism," Free Radical Biology and Medicine, vol. 35, no. 10, pp. 1185-1193, 2003.

[43] H. Yang, N. Magilnick, X. Ou, and S. C. Lu, "Tumour necrosis factor $\alpha$ induces co-ordinated activation of rat GSH synthetic enzymes via nuclear factor $\kappa \mathrm{B}$ and activator protein-1," Biochemical Journal, vol. 391, no. 2, pp. 399-408, 2005.

[44] S. C. Lu, "Regulation of glutathione synthesis," Molecular Aspects of Medicine, vol. 30, no. 1-2, pp. 42-59, 2009.
[45] I. Rahman, C. A. D. Smith, F. Antonicelli, and W. MacNee, "Characterisation of $\gamma$-glutamylcysteine synthetase-heavy subunit promoter: a critical role for AP-1," FEBS Letters, vol. 427, no. 1, pp. 129-133, 1998.

[46] R. T. Mulcahy, M. A. Wartman, H. H. Bailey, and J. J. Gipp, "Constitutive and $\beta$-naphthoflavone-induced expression of the human $\gamma$-glutamylcysteine synthetase heavy subunit gene is regulated by a distal antioxidant response element/ TRE sequence," Journal of Biological Chemistry, vol. 272, no. 11, pp. 7445-7454, 1997.

[47] N. Nieto, M. Marí, and A. I. Cederbaum, "Cytochrome P450 $2 \mathrm{E} 1$ responsiveness in the promoter of glutamate-cysteine ligase catalytic subunit," Hepatology, vol. 37, no. 1, pp. 96106, 2003.

[48] F. Bea, F. N. Hudson, H. Neff-LaFord et al., "Homocysteine stimulates antioxidant response element-mediated expression of glutamate-cysteine ligase in mouse macrophages," Atherosclerosis, vol. 203, no. 1, pp. 105-111, 2009.

[49] J. Y. Kim, J. H. Yim, J. H. Cho et al., "Adrenomedullin regulates cellular glutathione content via modulation of $\gamma$ glutamate-cysteine ligase catalytic subunit expression," Endocrinology, vol. 147, no. 3, pp. 1357-1364, 2006.

[50] W. Langston, M. L. Circu, and T. Y. Aw, "Insulin stimulation of $\gamma$-glutamylcysteine ligase catalytic subunit expression increases endothelial GSH during oxidative stress: influence of low glucose," Free Radical Biology and Medicine, vol. 45, no. 11, pp. 1591-1599, 2008.

[51] J. W. Langston, W. Li, L. Harrison, and T. Y. Aw, "Activation of promoter activity of the catalytic subunit of $\gamma$ glutamylcysteine ligase (GCL) in brain endothelial cells by insulin requires antioxidant response element 4 and altered glycemic status: implication for GCL expression and GSH synthesis," Free Radical Biology and Medicine, vol. 51, no. 9, pp. 1749-1757, 2011.

[52] M. Okouchi, N. Okayama, J. S. Alexander, and T. Y. Aw, "NRF2-dependent glutamate-L-cysteine ligase catalytic subunit expression mediates insulin protection against hyperglycemia-induced brain endothelial cell apoptosis," Current Neurovascular Research, vol. 3, no. 4, pp. 249-261, 2006.

[53] S. V. Shenvi, E. J. Smith, and T. M. Hagen, “Transcriptional regulation of rat $\gamma$-glutamate cysteine ligase catalytic subunit gene is mediated through a distal antioxidant response element," Pharmacological Research, vol. 60, no. 4, pp. 229-236, 2009.

[54] J. M. Estrela, F. Gil, J. M. Vila, and J. Vina, “ $\alpha$-Adrenergic modulation of glutathione metabolism in isolated rat hepatocytes," American Journal of Physiology, vol. 255, no. 6, p. 18/6, 1988.

[55] W. M. Sun, Z. Z. Huang, and S. C. Lu, "Regulation of $\gamma$ glutamylcysteine synthetase by protein phosphorylation," Biochemical Journal, vol. 320, no. 1, pp. 321-328, 1996.

[56] H. R. Moinova and R. T. Mulcahy, "Up-regulation of the human $\gamma$-glutamylcysteine synthetase regulatory subunit gene involves binding of Nrf-2 to an electrophile responsive element," Biochemical and Biophysical Research Communications, vol. 261, no. 3, pp. 661-668, 1999.

[57] H. Zhang, N. Court, and H. J. Forman, "Submicromolar concentrations of 4-hydroxynonenal induce glutamate cysteine ligase expression in HBE1 cells," Redox Report, vol. 12, no. 1-2, pp. 101-106, 2007.

[58] H. Yang, N. Magilnick, C. Lee et al., "Nrf1 and Nrf2 regulate rat glutamate-cysteine ligase catalytic subunit transcription indirectly via NF- $\kappa \mathrm{B}$ and AP-1," Molecular and Cellular Biology, vol. 25, no. 14, pp. 5933-5946, 2005. 
[59] D. Dreher and A. F. Junod, "Differential effects of superoxide, hydrogen peroxide, and hydroxyl radical on intracellular calcium in human endothelial cells," Journal of Cellular Physiology, vol. 162, no. 1, pp. 147-153, 1995.

[60] A. Siflinger-Birnboim, H. Lum, P. J. Del Vecchio, and A. B. Malik, "Involvement of $\mathrm{Ca}^{2+}$ in the $\mathrm{H}_{2} \mathrm{O}_{2}$-induced increase in endothelial permeability," American Journal of PhysiologyLung Cellular and Molecular Physiology, vol. 270, no. 6, pp. L973-L978, 1996.

[61] D. M. Shasby, S. E. Lind, and S. S. Shasby, "Reversible oxidant-induced increases in albumin transfer across cultured endothelium: alterations in cell shape and calcium homeostasis," Blood, vol. 65, no. 3, pp. 605-614, 1985.

[62] S. Lopez-Ongil, G. Torrecillas, D. Perez-Sala, L. GonzalezSantiago, M. Rodriguez-Puyol, and D. Rodriguez-Puyol, "Mechanisms involved in the contraction of endothelial cells by hydrogen peroxide," Free Radical Biology and Medicine, vol. 26, no. 5-6, pp. 501-510, 1999.

[63] S. Kastenbauer, U. Koedel, and H. W. Pfister, "Role of peroxynitrite as a mediator of pathophysiological alterations in experimental pneumococcal meningitis," Journal of Infectious Diseases, vol. 180, no. 4, pp. 1164-1170, 1999.

[64] N. Kuzkaya, N. Weissmann, D. G. Harrison, and S. Dikalov, "Interactions of peroxynitrite, tetrahydrobiopterin, ascorbic acid, and thiols: implications for uncoupling endothelial nitric-oxide synthase," Journal of Biological Chemistry, vol. 278, no. 25, pp. 22546-22554, 2003.

[65] U. Förstermann, "Endothelial NO synthase as a source of NO and superoxide," European Journal of Clinical Pharmacology, vol. 62 , no. 13 , pp. 5-12, 2006.

[66] B. T. Hawkins and T. P. Davis, "The blood-brain barrier/ neurovascular unit in health and disease," Pharmacological Reviews, vol. 57, no. 2, pp. 173-185, 2005.

[67] C. G. Kevil, N. Okayama, and J. S. Alexander, " $\mathrm{H}_{2} \mathrm{O}_{2}$-mediated permeability II: importance of tyrosine phosphatase and kinase activity," American Journal of Physiology, vol. 281, no. 6, pp. C1940-C1947, 2001.

[68] C. G. Kevil, T. Oshima, B. Alexander, L. L. Coe, and J. S. Alexander, " $\mathrm{H}_{2} \mathrm{O}_{2}$-mediated permeability: role of MAPK and occludin," American Journal of Physiology, vol. 279, no. 1, pp. C21-C30, 2000.

[69] M. Konstantoulaki, P. Kouklis, and A. B. Malik, "Protein kinase $\mathrm{C}$ modifications of VE-cadherin, p120, and $\beta$-catenin contribute to endothelial barrier dysregulation induced by thrombin," American Journal of Physiology, vol. 285, no. 2, pp. L434-L442, 2003.

[70] A. W. Stitt, A. J. Jenkins, and M. E. Cooper, "Advanced glycation end products and diabetic complications," Expert Opinion on Investigational Drugs, vol. 11, no. 9, pp. 1205-1223, 2002.

[71] P. S. Padayatti, A. S. Ng, K. Ucbida, M. A. Glomb, and R. H. Nagaraj, "Argpyrimidine, a blue fluorophore in human lens proteins: high levels in brunescent cataractous lenses," Investigative Ophthalmology and Visual Science, vol. 42, no. 6, pp. 1299-1304, 2001.

[72] D. S. C. Raj, G. Lim, M. Levi, C. Qualls, and S. K. Jain, "Advanced glycation End products and oxidative stress are increased in chronic allograft nephropathy," American Journal of Kidney Diseases, vol. 43, no. 1, pp. 154-160, 2004.

[73] S. P. Baba, O. A. Barski, Y. Ahmed et al., "Reductive metabolism of AGE precursors: a metabolic route for preventing AGE accumulation in cardiovascular tissue," Diabetes, vol. 58, no. 11, pp. 2486-2497, 2009.
[74] C. G. Schalkwijk, J. Van Bezu, R. C. Van Der Schors, K. Uchida, C. D. A. Stehouwer, and V. W. M. Van Hinsbergh, "Heat-shock protein 27 is a major methylglyoxal-modified protein in endothelial cells," FEBS Letters, vol. 580, no. 6, pp. 1565-1570, 2006.

[75] D. Yao, T. Taguchi, T. Matsumura et al., "High glucose increases angiopoietin-2 transcription in microvascular endothelial cells through methylglyoxal modification of mSin3A," Journal of Biological Chemistry, vol. 282, no. 42, pp. 31038-31045, 2007.

[76] C. F. Bento, F. Marques, R. Fernandes, and P. Pereira, "Methylglyoxal alters the function and stability of critical components of the protein quality control," PLOS ONE, vol. 5, no. 9, Article ID e13007, 2010.

[77] D. Dobler, N. Ahmed, L. Song, K. E. Eboigbodin, and P. J. Thornalley, "Increased dicarbonyl metabolism in endothelial cells in hyperglycemia induces anoikis and impairs angiogenesis by RGD and GFOGER motif modification," Diabetes, vol. 55, no. 7, pp. 1961-1969, 2006.

[78] H. S. Yim, S. O. Kang, Y. C. Hah, P. B. Chock, and M. B. Yim, "Free radicals generated during the glycation reaction of amino acids by methylglyoxal. A model study of proteincross-linked free radicals," Journal of Biological Chemistry, vol. 270, no. 47, pp. 28228-28233, 1995.

[79] N. Miyazawa, M. Abe, T. Souma et al., "Methylglyoxal augments intracellular oxidative stress in human aortic endothelial cells," Free Radical Research, vol. 44, no. 1, pp. 101-107, 2010.

[80] A. Dhar, I. Dhar, K. M. Desai, and L. Wu, "Methylglyoxal scavengers attenuate endothelial dysfunction induced by methylglyoxal and high concentrations of glucose," British Journal of Pharmacology, vol. 161, no. 8, pp. 1843-1856, 2010.

[81] M. Mukohda, H. Yamawaki, M. Okada, and Y. Hara, "Methylglyoxal augments angiotensin II-induced contraction in rat isolated carotid artery," Journal of Pharmacological Sciences, vol. 114, no. 4, pp. 390-398, 2010.

[82] O. Brouwers, P. M. Niessen, G. Haenen et al., "Hyperglycaemia-induced impairment of endothelium-dependent vasorelaxation in rat mesenteric arteries is mediated by intracellular methylglyoxal levels in a pathway dependent on oxidative stress," Diabetologia, vol. 53, no. 5, pp. 989-1000, 2010.

[83] K. Takahashi, R. Tatsunami, T. Oba, and Y. Tampo, "Buthionine sulfoximine promotes methylglyoxal-induced apoptotic cell death and oxidative stress in endothelial cells," Biological and Pharmaceutical Bulletin, vol. 33, no. 4, pp. 556-560, 2010.

[84] S. M. Sliman, T. D. Eubank, S. R. Kotha et al., "Hyperglycemic oxoaldehyde, glyoxal, causes barrier dysfunction, cytoskeletal alterations, and inhibition of angiogenesis in vascular endothelial cells: aminoguanidine protection," Molecular and Cellular Biochemistry, vol. 333, no. 1-2, pp. 9-26, 2010.

[85] A. Murray, "Cell cycle checkpoints," Current Opinion in Cell Biology, vol. 6, no. 6, pp. 872-876, 1994.

[86] E. H. Sarsour, M. G. Kumar, L. Chaudhuri, A. L. Kalen, and P. C. Goswami, "Redox control of the cell cycle in health and disease," Antioxidants and Redox Signaling, vol. 11, no. 12, pp. 2985-3011, 2009.

[87] B. P. Tu, A. Kudlicki, M. Rowicka, and S. L. McKnight, "Cell biology: logic of the yeast metabolic cycle: temporal compartmentalization of cellular processes," Science, vol. 310, no. 5751, pp. 1152-1158, 2005.

[88] S. G. Menon, E. H. Sarsour, D. R. Spitz et al., "Redox regulation of the $\mathrm{G} 1$ to $S$ phase transition in the mouse embryo 
fibroblast cell cycle1," Cancer Research, vol. 63, no. 9, pp. 2109-2117, 2003.

[89] J. E. Conour, W. V. Graham, and H. R. Gaskins, "A combined in vitro/bioinformatic investigation of redox regulatory mechanisms governing cell cycle progression," Physiological Genomics, vol. 18, pp. 196-205, 2004.

[90] W. C. Burhans and N. H. Heintz, "The cell cycle is a redox cycle: linking phase-specific targets to cell fate," Free Radical Biology and Medicine, vol. 47, no. 9, pp. 1282-1293, 2009.

[91] S. G. Menon and P. C. Goswami, "A redox cycle within the cell cycle: ring in the old with the new," Oncogene, vol. 26, no. 8, pp. 1101-1109, 2007.

[92] L. Latella, A. Sacco, D. Pajalunga et al., "Reconstitution of cyclin D1-associated kinase activity drives terminally differentiated cells into the cell cycle," Molecular and Cellular Biology, vol. 21, no. 16, pp. 5631-5643, 2001.

[93] P. M. Burch and N. H. Heintz, "Redox regulation of cellcycle re-entry: cyclin D1 as a primary target for the mitogenic effects of reactive oxygen and nitrogen species," Antioxidants and Redox Signaling, vol. 7, no. 5-6, pp. 741-751, 2005.

[94] P. A. Savitsky and T. Finkel, "Redox regulation of Cdc25C," Journal of Biological Chemistry, vol. 277, no. 23, pp. 2053520540, 2002.

[95] A. Yamauchi and E. T. Bloom, "Control of cell cycle progression in human natural killer cells through redox regulation of expression and phosphorylation of retinoblastoma gene product protein," Blood, vol. 89, no. 11, pp. 4092-4099, 1997.

[96] S. G. Menon, M. C. Coleman, S. A. Walsh, D. R. Spitz, and P. C. Goswami, "Differential susceptibility of nonmalignant human breast epithelial cells and breast cancer cells to thiol antioxidant-induced G1-delay," Antioxidants and Redox Signaling, vol. 7, no. 5-6, pp. 711-718, 2005.

[97] N. Kawamura, "Cytochemical and quantitative study of protein-bound sulfhydryl and disulfide groups in eggs of Arbacia during the first cleavage," Experimental Cell Research, vol. 20, no. 1, pp. 127-138, 1960.

[98] P. Diaz Vivancos, T. Wolff, J. Markovic, F. V. Pallardo, and C. H. Foyer, "A nuclear glutathione cycle within the cell cycle," Biochemical Journal, vol. 431, no. 2, pp. 169-178, 2010.

[99] D. W. Voehringer, D. J. Mcconkey, T. J. Mcdonnell, S. Brisbay, and R. E. Meyn, "Bcl-2 expression causes redistribution of glutathione to the nucleus," Proceedings of the National Academy of Sciences of the United States of America, vol. 95, no. 6, pp. 2956-2960, 1998.

[100] F. V. Pallardo, J. Markovic, J. L. Garcia, and J. Vina, "Role of nuclear glutathione as a key regulator of cell proliferation," Molecular Aspects of Medicine, vol. 30, no. 1-2, pp. 77-85, 2009.

[101] C. R. Jonas, T. R. Ziegler, L. H. Gu, and D. P. Jones, "Extracellular thiol/disulfide redox state affects proliferation rate in a human colon carcinoma (Caco2) cell line," Free Radical Biology and Medicine, vol. 33, no. 11, pp. 1499-1506, 2002.

[102] D. T. Dexter, C. J. Carter, F. R. Wells et al., "Basal lipid peroxidation in substantia nigra is increased in Parkinson's disease," Journal of Neurochemistry, vol. 52, no. 2, pp. 381389, 1989.

[103] J. Sian, D. T. Dexter, A. J. Lees et al., "Alterations in glutathione levels in Parkinson's disease and other neurodegenerative disorders affecting basal ganglia," Annals of Neurology, vol. 36, no. 3, pp. 348-355, 1994.

[104] S. J. Hemmings and K. B. Storey, "Brain gamma-glutamyltranspeptidase: characteristics, development and thyroid hormone dependency of the enzyme in isolated microvessels and neuronal/glial cell plasma membranes,"
Molecular and Cellular Biochemistry, vol. 202, no. 1-2, pp. 119-130, 1999.

[105] H. C. Bauer, U. Tontsch, A. Amberger, and H. Bauer, "Gamma-glutamyl-transpeptidase (GGTP) and NA+K(+)ATPase activities in different subpopulations of cloned cerebral endothelial cells: responses to glial stimulation," Biochemical and Biophysical Research Communications, vol. 168, no. 1, pp. 358-363, 1990.

[106] L. Atzori, J. M. Dypbukt, K. Sundqvist et al., "Growthassociated modifications of low-molecular-weight thiols and protein sulfhydryls in human bronchial fibroblasts," Journal of Cellular Physiology, vol. 143, no. 1, pp. 165-171, 1990.

[107] M. Thomas, T. Nicklee, and D. W. Hedley, "Differential effects of depleting agents on cytoplasmic and nuclear nonprotein sulphydryls: a fluorescence image cytometry study," British Journal of Cancer, vol. 72, no. 1, pp. 45-50, 1995.

[108] J. M. Starr, J. M. Wardlaw, K. Ferguson, A. MacLullich, I. J. Deary, and I. Marshall, "Increased blood-brain barrier permeability in type II diabetes demonstrated by gadolinium magnetic resonance imaging," Journal of Neurology Neurosurgery and Psychiatry, vol. 74, no. 1, pp. 70-76, 2003.

[109] J. D. Huber, R. L. VanGilder, and K. A. Houser, "Streptozotocin-induced diabetes progressively increases bloodbrain barrier permeability in specific brain regions in rats," American Journal of Physiology, vol. 291, no. 6, pp. H2660H2668, 2006.

[110] Y. Yang, E. Y. Estrada, J. F. Thompson, W. Liu, and G. A. Rosenberg, "Matrix metalloproteinase-mediated disruption of tight junction proteins in cerebral vessels is reversed by synthetic matrix metalloproteinase inhibitor in focal ischemia in rat," Journal of Cerebral Blood Flow and Metabolism, vol. 27, no. 4, pp. 697-709, 2007.

[111] P. L. Li, H. Hong, M. L. Jian et al., "Upregulation of RAGE at the blood-brain barrier in streptozotocin-induced diabetic mice," Synapse, vol. 63, no. 8, pp. 636-642, 2009.

[112] W. H. Hoffman, S. M. Stamatovic, and A. V. Andjelkovic, "Inflammatory mediators and blood brain barrier disruption in fatal brain edema of diabetic ketoacidosis," Brain Research C, vol. 1254, pp. 138-148, 2009.

[113] H. Liu, X. Liu, L. Jia et al., "Insulin therapy restores impaired function and expression of P-glycoprotein in blood-brain barrier of experimental diabetes," Biochemical Pharmacology, vol. 75, no. 8, pp. 1649-1658, 2008.

[114] D. F. Muresanu, A. Sharma, and H. S. Sharma, "Diabetes aggravates heat stress-induced blood-brain barrier breakdown, reduction in cerebral blood flow, edema formation, and brain pathology: possible neuroprotection with growth hormone," Annals of the New York Academy of Sciences, vol. 1199, pp. 15-26, 2010.

[115] M. A. El-Missiry and A. M. El Gindy, "Amelioration of alloxan induced diabetes mellitus and oxidative stress in rats by oil of Eruca sativa seeds," Annals of Nutrition and Metabolism, vol. 44, no. 3, pp. 97-100, 2000.

[116] M. H. Abdel-Wahab and A. R. A. Abd-Allah, "Possible protective effect of melatonin and/or desferrioxamine against streptozotocin-induced hyperglycaemia in mice," Pharmacological Research, vol. 41, no. 5, pp. 533-537, 2000.

[117] I. K. Mohan and U. N. Das, "Effect of L-arginine-nitric oxide system on chemical-induced diabetes mellitus," Free Radical Biology and Medicine, vol. 25, no. 7, pp. 757-765, 1998.

[118] P. L. Montilla, J. F. Vargas, I. F. Tunez, M. C. Munoz de Agueda, M. E. Valdelvira, and E. S. Cabrera, "Oxidative stress in diabetic rats induced by streptozotocin: protective effects 
of melatonin," Journal of Pineal Research, vol. 25, no. 2, pp. 94-100, 1998.

[119] I. G. Obrosova, L. Fathallah, H. J. Lang, and D. A. Greene, "Evaluation of a sorbitol dehydrogenase inhibitor on diabetic peripheral nerve metabolism: a prevention study," Diabetologia, vol. 42, no. 10, pp. 1187-1194, 1999.

[120] I. G. Obrosova and M. J. Stevens, "Effect of dietary taurine supplementation on $\mathrm{GSH}$ and $\mathrm{NAD}(\mathrm{P})$-redox status, lipid peroxidation, and energy metabolism in diabetic precataractous lens," Investigative Ophthalmology and Visual Science, vol. 40, no. 3, pp. 680-688, 1999.

[121] M. Okouchi, N. Okayama, and T. Y. Aw, "Differential susceptibility of naive and differentiated PC-12 cells to methylglyoxal-induced apoptosis: influence of cellular redox," Current Neurovascular Research, vol. 2, no. 1, pp. 13-22, 2005.

[122] K. Namba, Y. Takeda, K. Sunami, and M. Hirakawa, “Temporal profiles of the levels of endogenous antioxidants after four-vessel occlusion in rats," Journal of Neurosurgical Anesthesiology, vol. 13, no. 2, pp. 131-137, 2001.

[123] E. M. Park, J. H. Choi, J. S. Park, M. Y. Han, and Y. M. Park, "Measurement of glutathione oxidation and 8-hydroxy-2'deoxyguanosine accumulation in the gerbil hippocampus following global ischemia," Brain Research Protocols, vol. 6, no. 1-2, pp. 25-32, 2000.

[124] T. Mizui, H. Kinouchi, and P. H. Chan, "Depletion of brain glutathione by buthionine sulfoximine enhances cerebral ischemic injury in rats," American Journal of Physiology, vol. 262, no. 2, pp. H313-H317, 1992.

[125] H. Shimizu, Y. Kiyohara, I. Kato et al., "Relationship between plasma glutathione levels and cardiovascular disease in a defined population: the Hisayama study," Stroke, vol. 35, no. 9, pp. 2072-2077, 2004.

[126] M. Lafon-Cazal, S. Pietri, M. Culcasi, and J. Bockaert, "NMDA-dependent superoxide production and neurotoxicity," Nature, vol. 364, no. 6437, pp. 535-537, 1993.

[127] C. A. Piantadosi and J. Zhang, "Mitochondrial generation of reactive oxygen species after brain ischemia in the rat," Stroke, vol. 27, no. 2, pp. 327-332, 1996.

[128] S. A. Lipton and P. A. Rosenberg, "Mechanisms of disease: excitatory amino acids as a final common pathway for neurologic disorders," New England Journal of Medicine, vol. 330, no. 9, pp. 613-622, 1994.

[129] C. Iadecola, C. Forster, S. Nogawa, H. B. Clark, and M. E. Ross, "Cyclooxygenase-2 immunoreactivity in the human brain following cerebral ischemia," Acta Neuropathologica, vol. 98, no. 1, pp. 9-14, 1999.

[130] Y. Matsuo, T. Kihara, M. Ikeda, M. Ninomiya, H. Onodera, and K. Kogure, "Role of neutrophils in radical production during ischemia and reperfusion of the rat brain: effect of neutrophil depletion on extracellular ascorbyl radical formation," Journal of Cerebral Blood Flow and Metabolism, vol. 15, no. 6, pp. 941-947, 1995.

[131] A. Schrammel, A. C. F. Gorren, K. Schmidt, S. Pfeiffer, and B. Mayer, "S-nitrosation of glutathione by nitric oxide, peroxynitrite, and $\cdot \mathrm{NO} / \mathrm{O} 2^{\cdot-}$," Free Radical Biology and Medicine, vol. 34, no. 8, pp. 1078-1088, 2003.

[132] V. Angeli, A. Tacito, A. Paolicchi et al., "A kinetic study of gamma-glutamyltransferase (GGT)-mediated S-nitrosoglutathione catabolism," Archives of Biochemistry and Biophysics, vol. 481, no. 2, pp. 191-196, 2009.

[133] E. Bramanti, V. Angeli, M. Franzini et al., "Exogenous vs. endogenous gamma-glutamyltransferase activity: implications for the specific determination of S-nitrosoglutathione in biological samples," Archives of Biochemistry and Biophysics, vol. 487, no. 2, pp. 146-152, 2009.

[134] Y. B. Choi, L. Tenneti, D. A. Le et al., "Molecular basis of NMDA receptor-coupled ion channel modulation by Snitrosylation," Nature Neuroscience, vol. 3, no. 1, pp. 15-21, 2000.

[135] J. S. Stamler, E. J. Toone, S. A. Lipton, and N. J. Sucher, "(S)NO signals: translocation, regulation, and a consensus motif," Neuron, vol. 18, no. 5, pp. 691-696, 1997.

[136] M. Khan, H. Sakakima, T. S. Dhammu et al., "S-Nitrosoglutathione reducesoxidative injury and promotes mechanisms of neurorepair following traumatic brain injury in rats," Journal of Neuroinflammation, vol. 8, p. 78, 2011.

[137] P. Rauhala, A. M.-Y. Lin, and C. C. Chiueh, "Neuroprotection by S-nitrosoglutathione of brain dopamine neurons from oxidative stress," FASEB Journal, vol. 12, no. 2, pp. 165-173, 1998.

[138] Y. R. Kuo, F. S. Wang, S. F. Jeng, B. S. Lutz, H. C. Huang, and K. D. Yang, "Nitrosoglutathione improves blood perfusion and flap survival by suppressing iNOS but protecting eNOS expression in the flap vessels after ischemia/reperfusion injury," Surgery, vol. 135, no. 4, pp. 437-446, 2004.

[139] M. Khan, Y. B. Im, A. Shunmugavel et al., "Administration of S-nitrosoglutathione after traumatic brain injury protects the neurovascular unit and reduces secondary injury in a rat model of controlled cortical impact," Journal of Neuroinflammation, vol. 6, p. 32, 2009.

[140] M. Khan, M. Jatana, C. Elango, A. Singh Paintlia, A. K. Singh, and I. Singh, "Cerebrovascular protection by various nitric oxide donors in rats after experimental stroke," Nitric Oxide, vol. 15, no. 2, pp. 114-124, 2006.

[141] H. Wünsche, I. T. Baldwin, and J. Wu, "S-Nitrosoglutathione reductase (GSNOR) mediates the biosynthesis of jasmonic acid and ethylene induced by feeding of the insect herbivore Manduca sexta and is important for jasmonate-elicited responses in Nicotiana attenuata," Journal of Experimental Botany, vol. 62, no. 13, pp. 4605-4616, 2011.

[142] L. G. Que, Z. Yang, J. S. Stamler, N. L. Lugogo, and M. Kraft, "S-nitrosoglutathione reductase: an important regulator in human asthma," American Journal of Respiratory and Critical Care Medicine, vol. 180, no. 3, pp. 226-231, 2009.

[143] N. V. Marozkina, C. Wei, S. Yemen et al., "S-Nitrosoglutathione reductase in human lung cancer," American Journal of Respiratory Cell and Molecular Biology, vol. 46, no. 1, pp. 6370, 2012. 

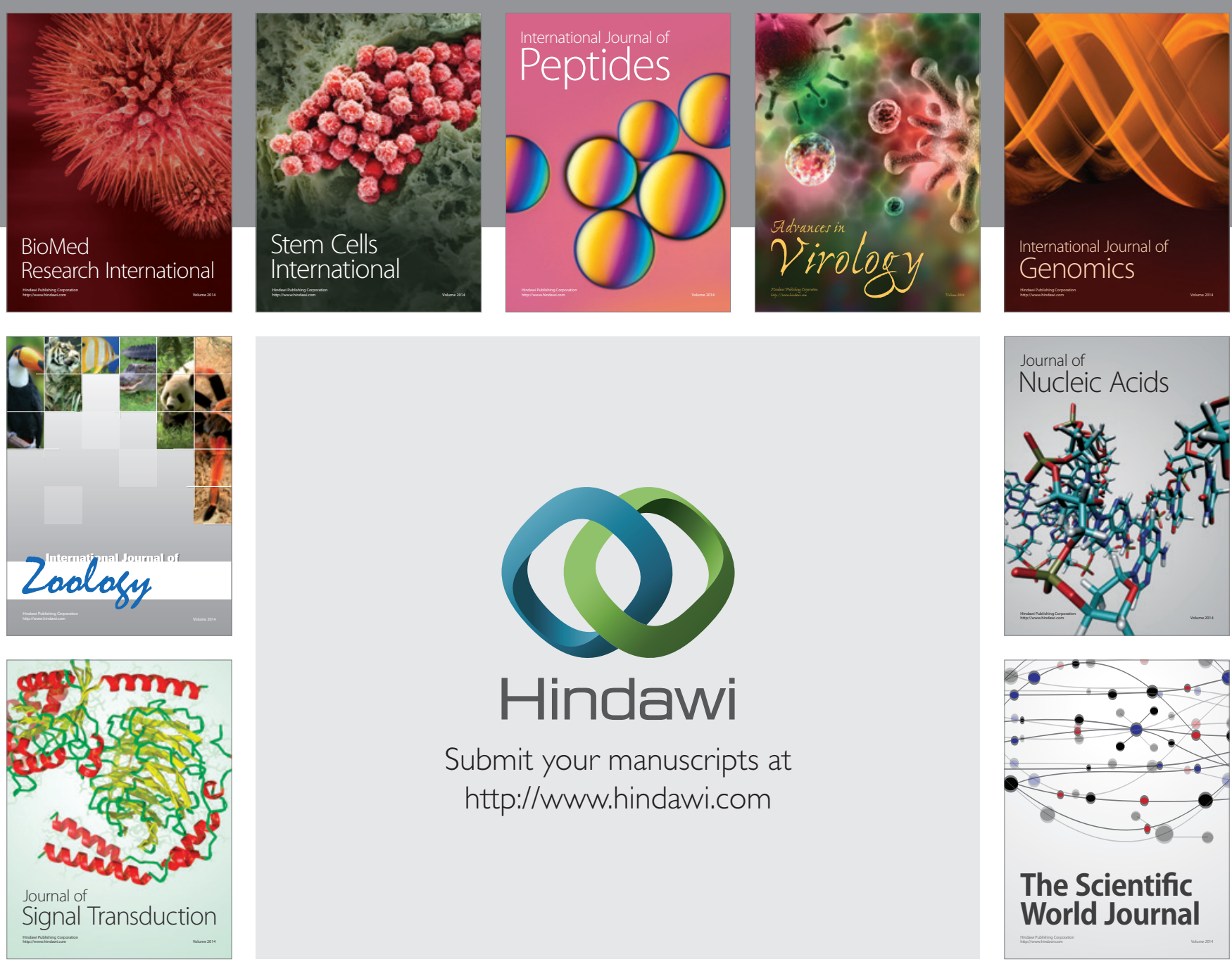

Submit your manuscripts at

http://www.hindawi.com
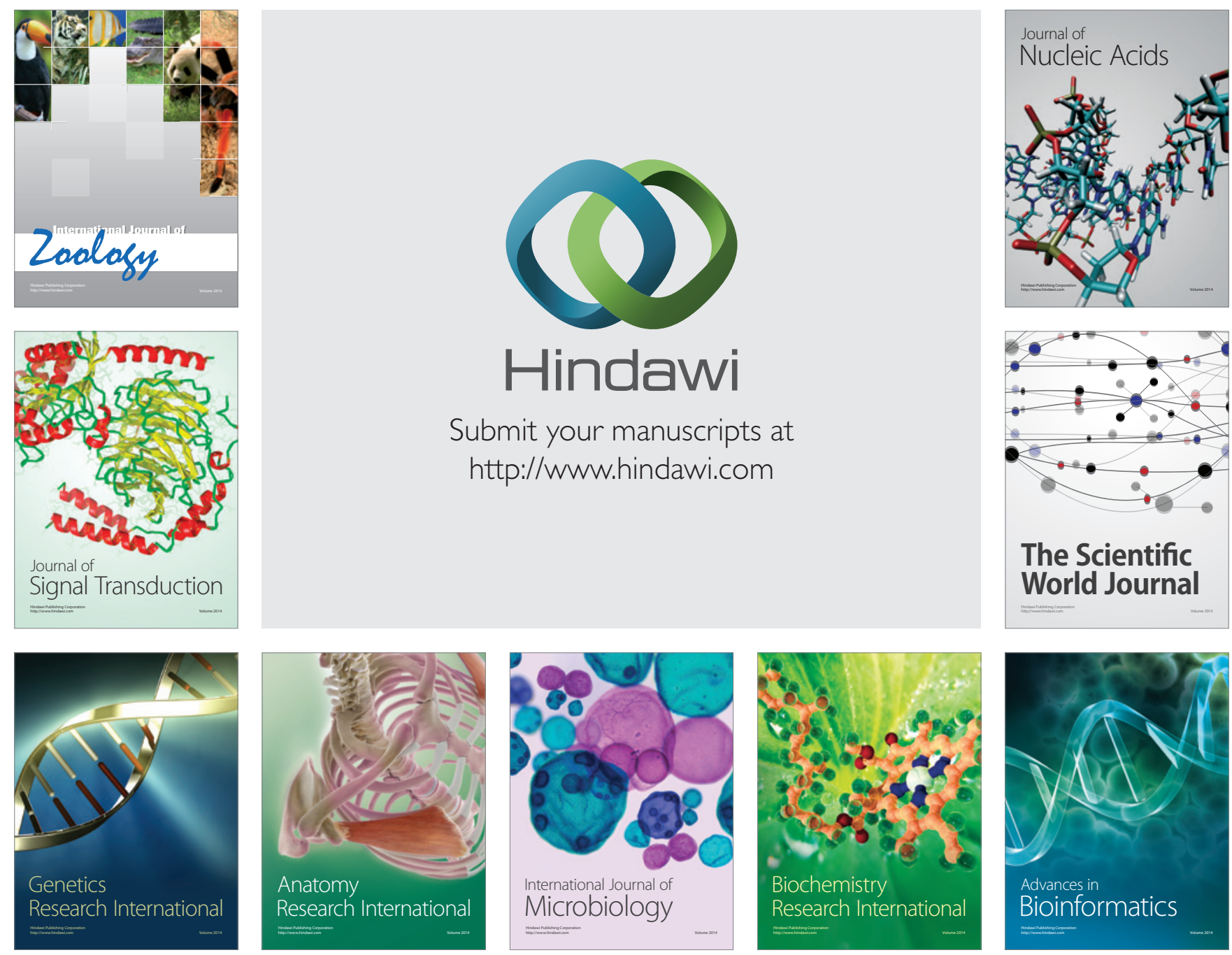

The Scientific World Journal
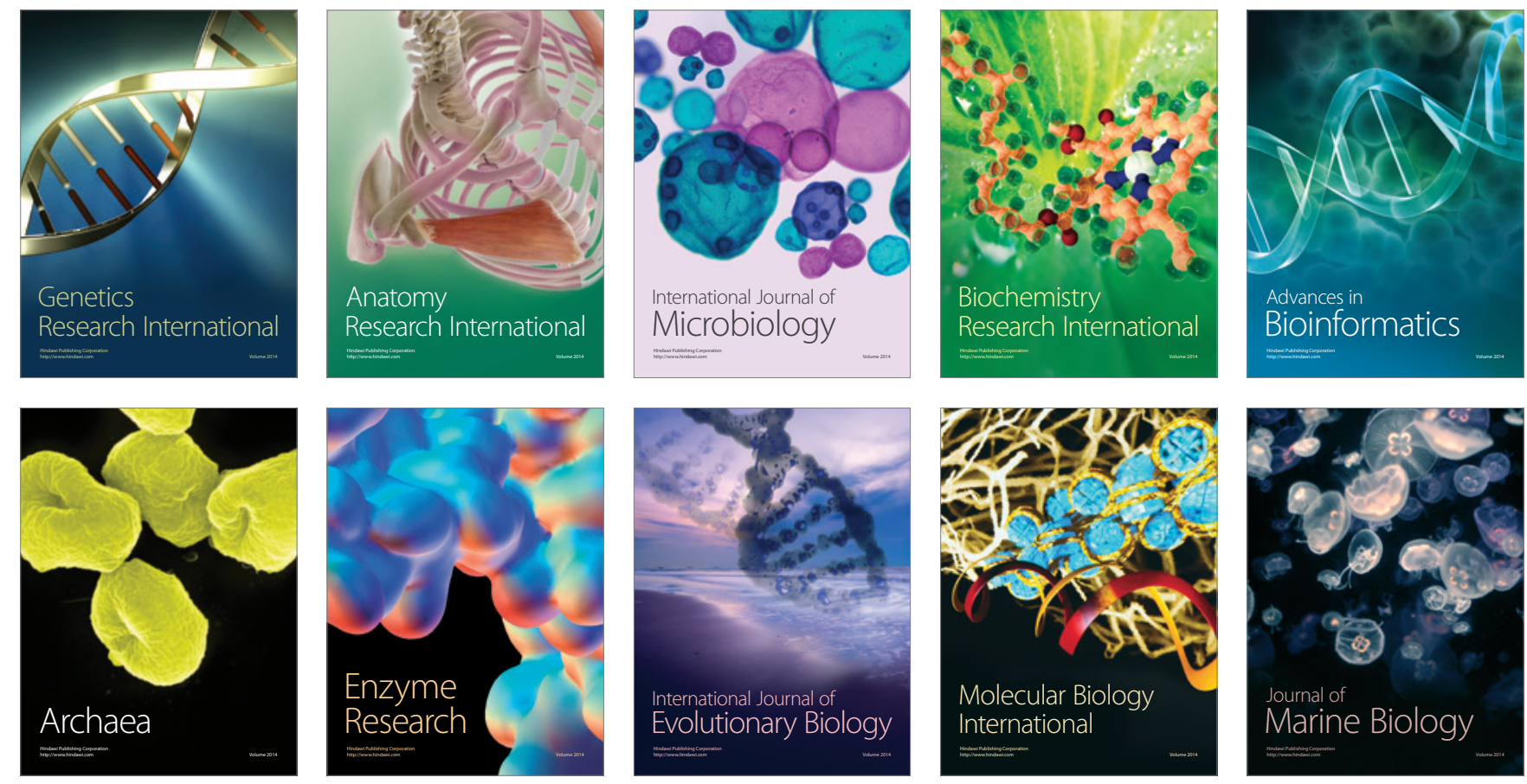